\title{
Assessing the potential of PV hybrid systems to cover HVAC loads in a grid- connected residential building through intelligent control
}

\author{
J.C. Solano , L. Olivieri, E. Caamaño-Martín
}

H I G H L I G H T S

- A grid connected PV-battery system model is proposed to supply HVAC loads.

- Two optimized control strategies for the battery energy storage system are proposed.

- Simulations are validated with actual data coming from the monitoring campaign.

- An economic assessment of the strategies, including sensitivity analysis are included.

Keywords:

PV hybrid

BESS

Battery control strategies

HVAC

PV-battery

\section{A B S T R A C T}

This paper presents theoretical and experimental work that is being carried out in a grid-connected residential building demonstrator available at the Instituto de Energía Solar (IES) of the Universidad Politécnica de Madrid (UPM) in Madrid, Spain. The house is provided with a building-integrated photovoltaic (PV) system coupled to a battery energy storage system (BESS), and a heating, ventilation, and air-conditioning system (HVAC) based on two air-to-air direct expansion reversible heat pumps. Thermal loads, HVAC consumption, and PV generation are simulated using different dynamic models, and they are validated with actual data derived from monitoring the experimental campaign. A model of intelligent control of BESS is proposed, which aims to supply the selected application (HVAC load) with two control strategies: increasing PV self-consumption and grid-peak shaving. This model has been validated with experimental data (error $<10 \%$ ). Furthermore, the study includes aging and degradation effects on the batteries to make allowance for realistic lifetime assessment. The results of the case study show that in a building without a BESS, the self-consumption rate is about 30\%; however, with the implementation of the proposed control, it could achieve approximately $50 \%$, depending on the BESS capacity and the PV generator nominal power. Likewise, by using a combination of both strategies, it is possible to reduce both contracted power and energy consumption ( $77 \%$ and $49 \%$ respectively for case study).

\section{Introduction}

Heating, Ventilations, and Air Conditioning systems (HVAC) represent between $40 \%$ and $60 \%$ of energy demand for buildings in Europe [1], and are also of increasing importance for buildings worldwide [2]. Despite the importance of thermal systems in the energy balance of buildings, existing research indicates that specific strategies for combining local photovoltaic (PV) generation with electricitypowered air conditioning equipment (especially reversible heat pumps) are still under examination [3-5].

In fact, the IEA Solar Heating and Cooling Programme has shown interest in these kinds of systems, particularly within its Task 53 [6]. Its main objective is to analyse the use of solar driven systems for cooling and heating, including PV driven systems, from both technical and economic points of view.

In a previous study by the authors [7], it was shown that annual billing for HVAC demand in commercial buildings could be reduced by up to $50 \%$ using PV solely without storage systems, primarily because thermal loads match reasonably well with PV energy production. In contrast, most of the HVAC consumption in the residential sector is time-shifted with respect to the PV generation. Therefore, the addition of a Battery Energy Storage System (BESS) is required in order to decouple generation and consumption, increasing the self-consumption rate.

Many studies simulating PV systems coupled to HVAC equipment have been published [8-12], demonstrating the interest of using PV 


\begin{tabular}{|c|c|c|c|}
\hline \multicolumn{2}{|c|}{ Nomenclature } & \multirow{3}{*}{$\begin{array}{l}P_{\text {bat }}^{*} \\
P_{\text {bat }} \\
P_{\text {grid }}\end{array}$} & \multirow{2}{*}{$\begin{array}{l}\text { battery power before inverter, } \mathrm{W} \\
\text { battery power after inverter, } \mathrm{W} \\
\text { instantaneous power exported or imported from the grid, }\end{array}$} \\
\hline$\Delta t$ & Time interval, $0-1 \mathrm{~h}$ & & \\
\hline C & Nominal capacity of the battery bank, Ah & & W \\
\hline DoD & battery depth of discharge, $1=$ empty; $0=$ full & $P_{L o L}$ & power demand not supplied by the system, W \\
\hline$E_{\text {charge }}$ & energy charged into the battery, $\mathrm{kWh}$ & $P_{\text {load }}$ & instantaneous power demand, $\mathrm{W}$ \\
\hline$E_{\text {discharge }}$ & energy discharged from the battery, kWh & $P_{\max }$ & maximum power imported from the grid, $\mathrm{W}$ \\
\hline$E_{L o L}$ & energy consumption not supplied by the system, kWh & $P_{\text {required }}$ & power required to complete charge's battery, W \\
\hline$E_{\text {load }}$ & energy consumption, kWh & $P_{\text {surplus }}$ & PV surplus power, W \\
\hline$E_{p v}$ & PV energy, kWh & SoC & battery state of charge, $0=$ empty; $1=$ full \\
\hline$G_{h r z}$ & global horizontal irradiation, $\mathrm{W} / \mathrm{m}^{2}$ & SoC $C_{\text {low }}$ & lower limit state of charge \\
\hline$h$ & hour $(1-24)$ & So $C_{\max }$ & maximum state of charge \\
\hline$k_{\mathrm{cn}}$ & efficiency coefficients of the inverter in charge, $[0-1]$ & $S o C_{\min }$ & minimum state of charge \\
\hline$L_{\text {discharge }}$ & losses in the battery inverter (discharge), $\%$ & $\varepsilon_{s c}$ & self-consumption, $\%$ \\
\hline$m$ & total number of samples & $\varepsilon_{s s}$ & self-sufficiency, \% \\
\hline$n$ & discrete time sample & & \\
\hline
\end{tabular}

energy to condition the indoor climate in buildings, despite not having been validated experimentally. Other studies have presented experimental results, such as [13] where the operation and the energy behaviour of an air conditioner simultaneously connected to the grid and a PV system were analysed. However, this system does not use a storage system. In another research [5], the performance of a solar PV driven air conditioner was experimentally analysed in the hot-summer and cold-winter zone in China, but it did not present control strategies or a model in a dynamic regime that would allow the determination of the system's behaviour for other operating conditions.

In the field of grid-connected PV-battery systems, several simulation-based studies have been proposed [14-17] that show the benefit of using a BESS to reduce grid electricity consumption. However, these studies do not present experimental data or control strategies based on PV generation, load condition, and battery state of charge.

As regards the economic viability of PV-battery systems, significant studies such as $[3,18-20]$ have been carried out. However, these studies are not intended to cover a specific load such as HVAC for both cooling and heating throughout the year, and they do not present the economic savings of PV-battery systems compared to other grid-connection scenarios.

In this context, the main objective of this work is to assess the technical and economic benefits of using PV hybrid system in combination with reversible heat pumps and optimised control strategies to supply HVAC loads in residential buildings. To meet this goal, a gridconnected PV-battery model is proposed. With the aim of increasing PV self-consumption and grid-peak shaving, two optimised control strategies for the BESS are proposed, simulated, and validated with actual data coming from the experimental campaign. Finally, an economic analysis is presented, which show the billing savings that the PV hybrid system would produce in comparison with a conventional system. Likewise, the levelized cost of electricity (LCOE) and the payback time were calculated by taking into account the current costs of both the PV system and the BESS as well as batteries' lifetime, equipment changes, and current electricity pricing.

Remarkable contributions involving modelling and control strategies in grid connected PV hybrid systems have been published and validated with experimental data [19,21-23]. Nevertheless, the present work proposes a dynamic model that differs from other similar models $[19,21,22,24-27]$ in five main aspects: (1) The model is optimised to operate with two control strategies at the same time maximizing selfconsumption and grid-peak shaving and giving the user the possibility of choosing one or the other, as presented in the case study. (2) The model can include $C$-rate data (C-rate is a measure of the rate at which a battery is discharged relative to its maximum capacity) to improve its accuracy. (3) The model includes a formulation to avoid over-charge and over-discharge of the battery by using adjustable values, and (4) the model includes calculation of losses in the battery inverter. The last two aspects are intrinsically related to the characteristics of the battery inverters where the control strategies can be ultimately implemented. Additionally, (5) the model presents a method to quantify the expected energy not supplied (EENS), which is also called 'Loss of Load' ( $L o L)$, terms used in research literature to show the amount of on-site generation that does not cover on-site demand [28-30]. This method is

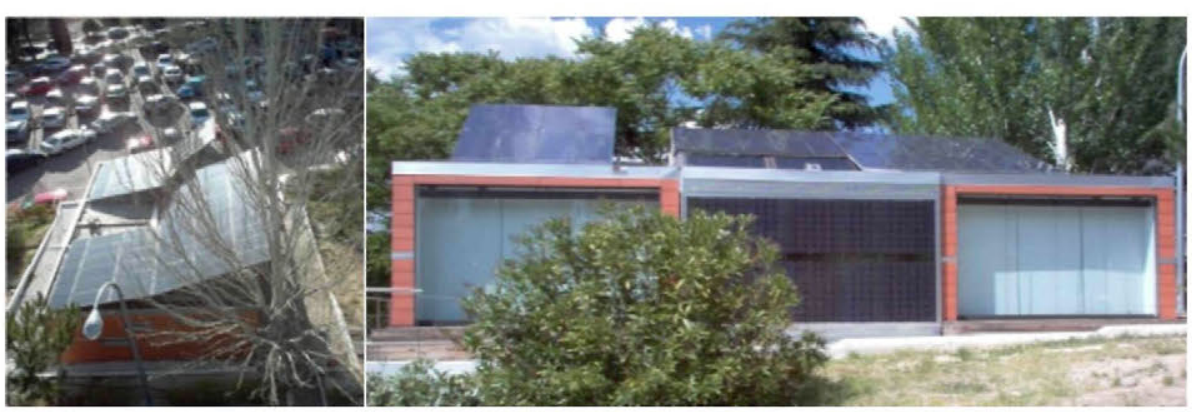

Fig. 1. Upper and frontal (south) views of Magic Box prototype. 
valid only when the grid-peak shaving control strategy is used, and it occurs when there is not enough PV generation, the minimum state of charge level of storage is reached, and principally due to power restriction in which power imported from the grid is not higher than contracted power. Although, in terms of realistic operation, the load will never be unserved: A penalty fee by the utility grid could be imposed, or high electricity prices could be applied. Thus, the $L o L$ rate can be used to design an optimal size for a PV-battery system to supply power and energy in terms of a particular application, in this case an HVAC load, as shown in the case study presented in Section 5.

This research has been developed in Spain at the premises of the Instituto de Energía Solar - Universidad Politécnica de Madrid (IES-UPM), where a prototype of a Zero-Energy Residential Building called 'Magic Box' has been installed since 2006 (Fig. 1). Magic Box was the first European entry in the Solar Decathlon international competition and has been recognized internationally as an outstanding urban-scale PV system integration project $[31,32]$. Several research initiatives have been carried out with the prototype $[26,33,34]$, such as the project 'Residential electricity demand side management with PV technology 2008-2010'. Within this project, the first theoretical and experimental evidence of the possibilities of performing an Active Demand Side Management (ADSM) of domestic electricity consumption was demonstrated worldwide.

\section{Methodology}

This research is based on experimental measurements that have been used to develop a theoretical model of a PV hybrid system. With this model, annual simulations have been performed in a MATLAB ${ }^{\oplus}$ programming environment.

The experimental process consisted of measurements that were recorded every minute and managed remotely through a data acquisition system. The system measured the values through sensors and then stored them through automated tasks performed by Ubuntu-Linux. The measured variables were as follows: global horizontal irradiance, outdoor temperature, indoor temperature, indoor relative humidity, indoor concentration of $\mathrm{CO}_{2}$, electricity consumption of the heat pumps, electricity generated by the PV system, grid power, battery power, and battery state of charge.
The simulation stage was divided into two distinct parts. For the first part, the grid power, the battery power, and the state of charge were simulated based on a model of PV hybrid system and control strategies developed within this research and presented in Section 4. The results obtained were compared and validated with experimental measurements presented in Section 4.7. For the second part, the electricity consumption of the heat pumps and the electricity generated by the PV system were simulated using validated tools presented in Sections 5.1 and 5.2 respectively, and the results were validated with experimental data.

\subsection{Relevant parameter}

To analyse the behaviour of the global system, the following parameters were considered in this paper:

(a) $P_{p v}$ : Power produced by the PV system

(b) $P_{\text {load }}$ : HVAC loads and corresponding electricity consumption of the heat pumps

(c) $P_{\text {grid }}:$ Exported/imported grid power

(d) $P_{b a t}:$ Charge/discharge battery power

(e) $\varepsilon_{s s}$ : Self-sufficiency, and $\varepsilon_{s c}$ : Self-consumption

(f) Economic analysis: LCOE, payback-time, and billing saving.

In Fig. 2a diagram of the input and output variables of the entire process is shown, and Fig. 3 shows the electrical scheme of the system.

\subsection{Experimental measurements}

\subsubsection{Heating, ventilation and air-conditioning system (HVAC)}

To determine the electricity consumption of HVAC thermal loads, two air-to-air electrical reversible heat pumps from Daikin (model FTX25KV1B) are used. This kind of heat pumps is experiencing a significant market penetration due to two main characteristics. First, using the same installation for both heating and cooling requirements can be met by simply inverting the operating cycle with a reversing valve. The second relevant advantage of these systems in comparison with other HVAC solutions is that both processes are developed with high efficiencies, which contribute to improving the overall energy efficiency of

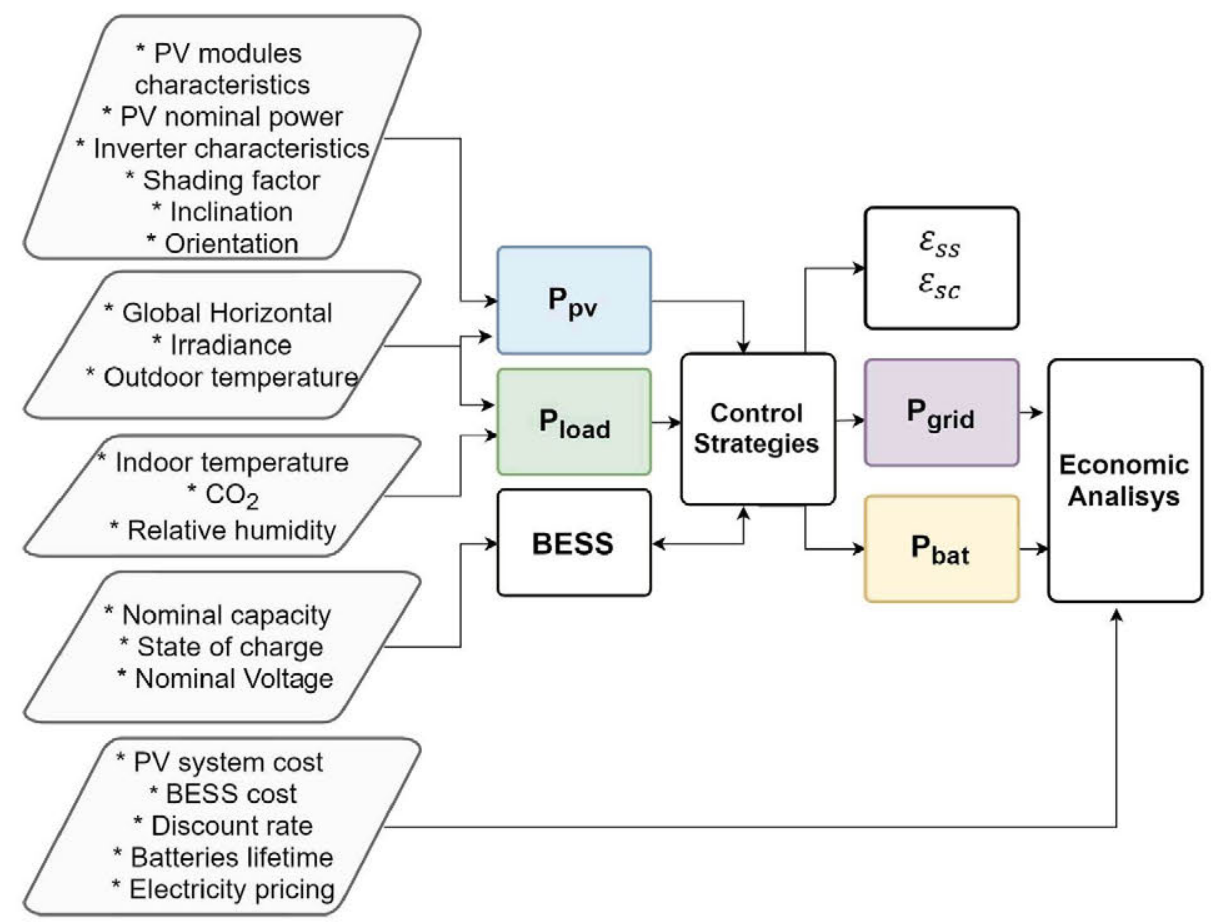

Fig. 2. Flowchart of relevant parameters. 


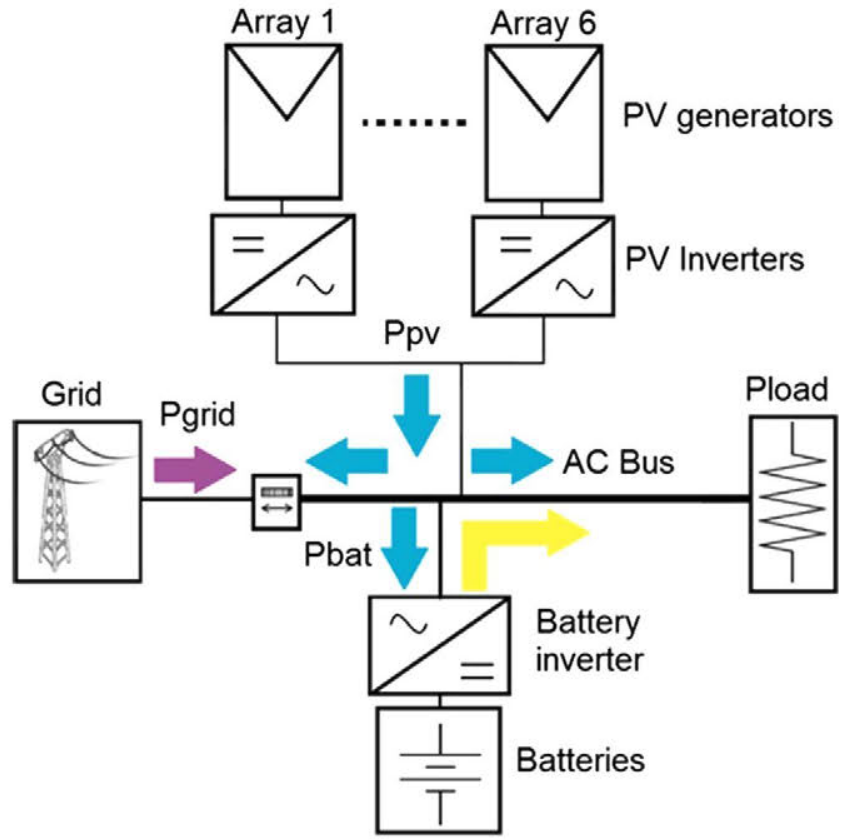

Fig. 3. Electrical scheme of the entire system.

the building.

In addition, to monitor the comfort conditions inside the house, STR100 thermistors from Schneider Electric with an accuracy of $\pm 0.35{ }^{\circ} \mathrm{C}$ are used to measure the indoor temperature. Likewise, relative humidity $(0-100 \%)$ and concentration of $\mathrm{CO}_{2}(0-2000 \mathrm{ppm})$ are measured by the SCR110 sensor from Schneider Electric with an accuracy of $\pm 2 \%$. The positions of these devices and sensors are shown in Fig. 4.

\subsubsection{PV system}

The PV systems of Magic Box consists of six independent monocrystalline silicon PV arrays (Fig. 5a) with $7 \mathrm{~kW}_{\mathrm{p}}$ of total nominal power. This system was designed to exploit the different tilts of the sun along the year. To achieve this goal, the PV system is distributed in different south-oriented surfaces, which allow one or more PV arrays to be used, depending on electrical consumption as discussed in Section 5.2 below. Each PV array has an associated string-type inverter, and therefore the PV AC power is supplied to a common AC bus (see Fig. 3).

The PV system also has a meteorological station with the following sensors: an Eppley pyranometer (first class pyranometer, according to ISO 9060) for measuring global horizontal solar radiation, and a platinum thermoresistance (PT-100) for the measurement of ambient temperature.

In Table 1, the main features for each PV array have been shown: tilt angle, nominal power $\left(P_{G}\right)$, inverter maximum power $\left(P_{i n v}\right)$, and the annual expected PV energy production ( $\left.E_{p v}\right)$ according to Madrid's typical meteorological year $[35,36]$. The PV generators have been illustrated in Fig. 5b.

\subsubsection{Battery energy storage system}

The house is equipped with a stationary lead-acid battery bank (Sonnenschein A602/625) with dryfit gel - VRLA (valve-regulated leadacid battery) technology. Lead-acid batteries are still widely used in both off-grid and grid-connected PV systems [18,37]. Lead-acid batteries are reliable, globally manufactured, and therefore, a widely understood technology. Furthermore, it has lower prices compared to other storage technologies for PV systems, such as Lithium batteries $[37,38]$. The VRLA technology also provides some advantages compared to other types of lead-acid batteries, such as no maintenance, high current capability, deep-discharge conditions, good power density, and wide operating temperature $[39,40]$.

The battery bank is divided into 24 cells, with each cell having a capacity $\left(\mathrm{C}_{10}\right)$ of $455 \mathrm{Ah}$ and a nominal voltage of $2 \mathrm{~V}$. Therefore, the total battery bank voltage is $48 \mathrm{~V}$, with a capacity of around $22 \mathrm{kWh}$. The storage system has a bidirectional battery inverter (SMA - Sunny

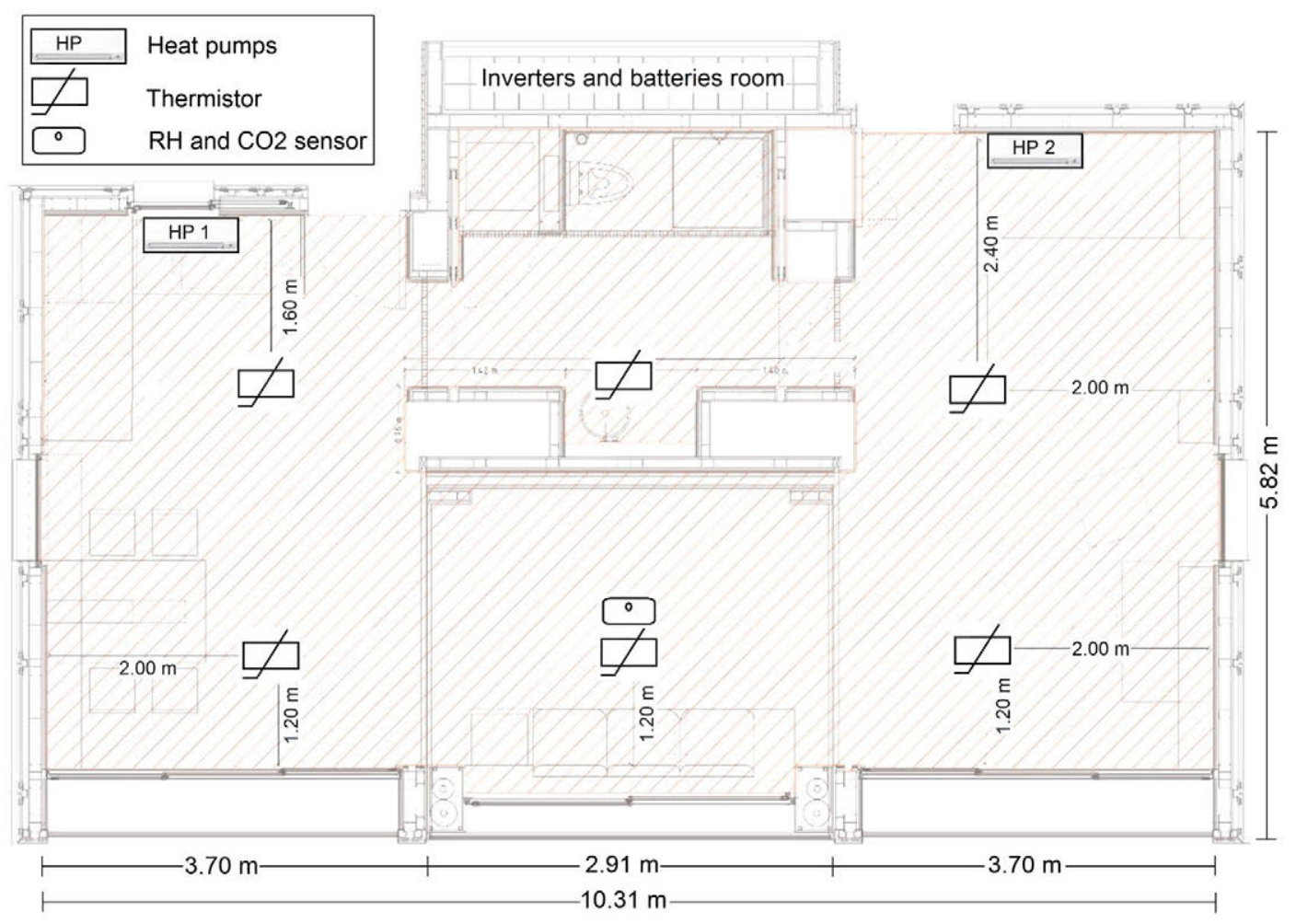

Fig. 4. Location scheme of heat pumps and indoor sensors. 


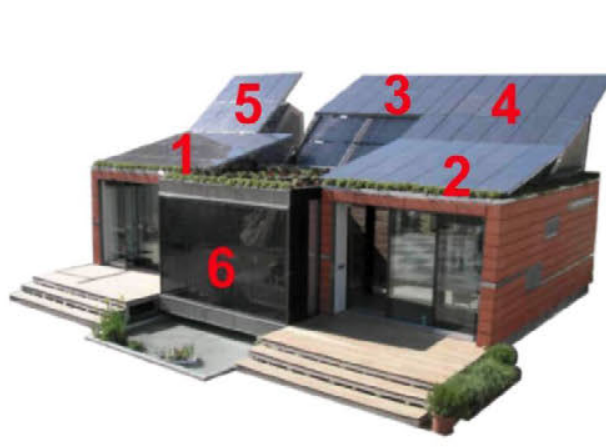

(a)

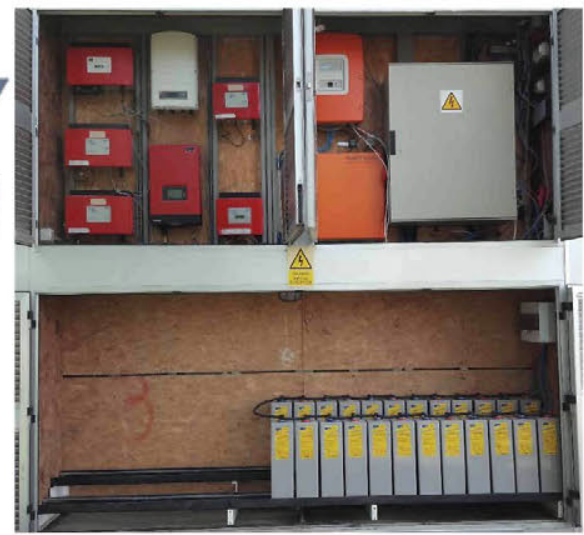

(b)
Fig. 5. (a) Distributions of PV arrays at the Magic Box. (b) Detail of the technical room with inverters.
Table 1

Characteristics of PV arrays.

\begin{tabular}{lllllll}
\hline Arrays & 1 & 2 & 3 & 4 & 5 & 6 \\
\hline Tilt & $12^{\circ}$ & $12^{\circ}$ & $25^{\circ}$ & $25^{\circ}$ & $38^{\circ}$ & $90^{\circ}$ \\
$P_{G}(\mathrm{~kW})$ & 1.45 & 1.44 & 1.34 & 1.34 & 0.80 & 0.61 \\
$P_{\text {inv }}(\mathrm{kW})$ & 1.50 & 1.50 & 1.50 & 1.50 & 1.00 & 0.60 \\
$E_{p v}(\mathrm{kWh})$ & 1745 & 1683 & 1774 & 1774 & 1026 & 572 \\
\hline
\end{tabular}

Backup 5000) for automatic switching between battery voltage at DC and all power exchanges produced through the AC bus. The battery inverter does not only implement the current conversion, it also allows for the controlling and monitoring of the power flows from and to the battery. This mechanism is implemented through a high-level software battery controller specifically developed in a previous study [26] in order to implement different control strategies. The inverters and batteries are placed in an appropriate location inside the house (Fig. $5 \mathrm{~b}$ ).

\section{Description of control strategies}

The general aim of implementing control strategies is to profit from the use of local PV production to provide an efficient supply to HVAC demand. Thus, the two proposed strategies have been implemented to control the BESS.

\subsection{Control strategy 1: maximize the use of PV energy (increasing PV self- consumption)}

In this strategy, the power generated by PV system supplies the HVAC demand; excess of PV charges the battery, and if the battery is full, PV surplus is exported to the grid. Likewise, from a demand-side point of view, HVAC demand is supplied first by PV. If more power is required, it is obtained from the battery, and finally, it is imported from the grid. It is noteworthy that a direct power exchange between the grid and the battery is not allowed in any circumstance.

\subsection{Control strategy 2: reduction of grid power (grid-peak shaving)}

In this strategy, as in strategy 1 , the power generated by the PV system supplies the HVAC demand, the excess of PV charges the battery, and if the battery is full, PV surplus is exported to the grid. From a demand-side point of view, strategy 2 is similar to strategy 1 ; the difference is that the battery is discharged only to supply power peaks. In fact, HVAC demand is supplied firstly by PV and then by the grid. However, in this case, the power supplied from the grid is limited to an established value $P_{\max }{ }^{1}$ If demand exceeds this limit, the battery is discharged so that the grid demand is curtailed. Also, in this case, power exchanges between grid and battery are not allowed.

The different operations of the control strategies are shown in Fig. 6. Fig. $6 \mathrm{a}$ shows the operation of strategy 1 and Fig. $6 \mathrm{~b}$ shows the operation of strategy 2 with an illustrative value of $P_{\max }=805 \mathrm{~W}$. Both strategies are illustrated for the same day, where $P_{b a t}, P_{\text {grid }}$ and $S o C$ are simulated based on experimental data of $P_{p v}$ and $P_{\text {load }}$.

As shown in Fig. 6a, the battery supplies (positive $P_{b a t}$ ) the HVAC demand until it reaches the minimum state of charge allowed (in this case $S o C_{\min }=20 \%$ ). Then, the required power is imported from the grid (positive $P_{\text {grid }}$ ). PV generation is used first to supply the local demand; the surplus of PV charges the battery (negative $P_{\text {bat }}$ ) up to $100 \%$, and the PV excess is exported to the grid (negative $P_{\text {grid }}$ ).

In strategy 2 (Fig. 6b), the battery reduces grid power demand over $P_{\max }$, which represents a reduction of the assumed initial contracted power required to supply the HVAC loads. However, in terms of grid energy savings, the outcome is minimal. The potential benefit of this control strategy can be explained by considering the impact that the contracted peak power has on the electricity bill, which strongly depends on the regulatory framework and/or billing contract conditions. In Spain, for instance, the power term has an impact on the electricity bill, increasing by nearly $100 \%$ since 2007 to the present day $[41,42]$. Therefore, a BESS control strategy focused on reducing power peaks supplied by the grid is worthy of study.

Different studies have proposed battery control strategies used with PV, related to strategy $1[19,22,24,43]$ or strategy $2[21,44-46]$ separately. This research proposes a unique model for both approaches, as shown in Sections 3.3 and 4, in order to perform annual simulations combining both control strategies for different approaches, such as seasonal periods, hourly electricity price, days of maximum solar irradiance, etc.

\subsection{Control algorithm}

The actual BESS is controlled by an algorithm developed in $C++$, whereby the battery inverter is used to provide relevant information ( $S o C$, battery charging current, grid current, battery voltage, etc.) through a serial communication protocol. Similarly, the algorithm has real-time access to the data acquisition system, where the values of $P_{\text {load }}$ and $P_{p v}$ are obtained. Once the data has been registered, the controller will act on the grid contactor and set the inverter's current limiters. The general scheme of the control algorithm implemented for both strategy

\footnotetext{
${ }^{1}$ In Spain, customers can choose the power to be contracted, according to normalized current values [57].
} 


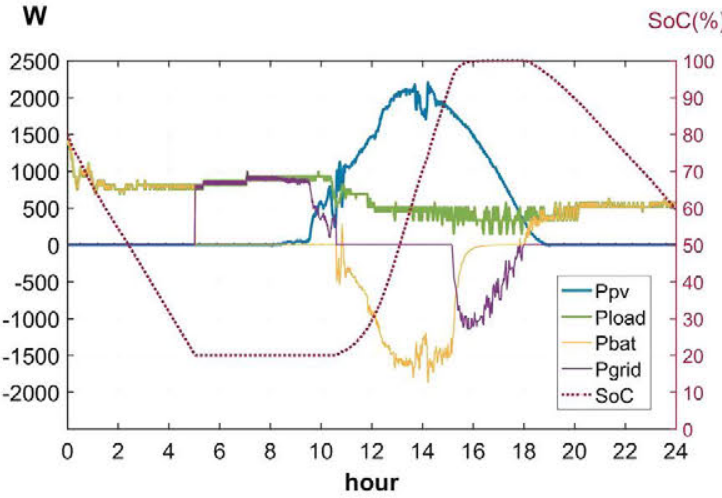

(a)

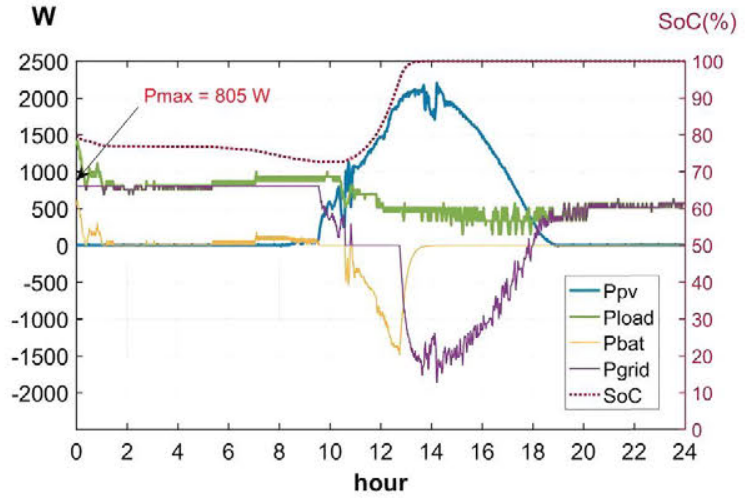

(b)

Fig. 6. Daily power flow of: (a) strategy 1 ; (b) strategy 2. $P_{p y}$ : PV power; $P_{\text {load }}$ : HVAC load; $P_{\text {bat: }}$ battery power; $P_{\text {grid: }}$ grid power; SoC: Battery state of charge.

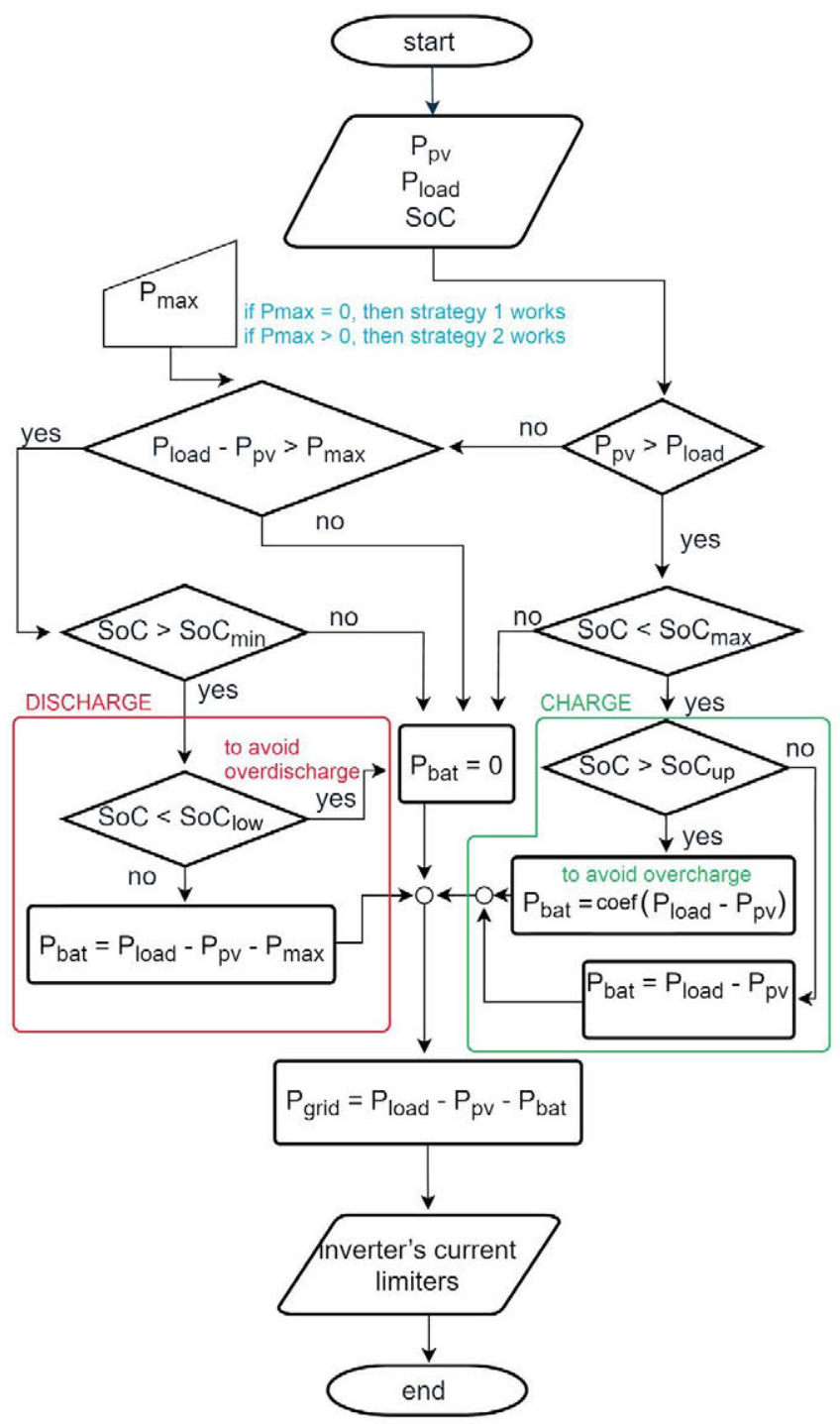

Fig. 7. Algorithm diagram that controls the battery inverter.

$1\left(P_{\max }=0\right)$ and strategy $2\left(P_{\max }>0\right)$ is presented in Fig. 7.

\section{Grid-connected PV-battery modelling}

The general formulation of the mathematical model presented here was designed to complement an existing control algorithm [26]. The improved model enables the choice between the two control strategies proposed, whereby the battery power, grid power exchange, battery state of charge, and self-consumption of the PV hybrid system are calculated.

\subsection{Battery charge}

When $P_{p v}[n]>P_{\text {load }}[n]$, the battery inverter works in self-consumption mode, and the battery bank is charged only with $P_{\text {surplus }}$. Then, the battery power $P_{b a t}^{*}[n]$ is calculated for each discrete time step $n$ :

$P_{\text {bat }}^{*}[n]= \begin{cases}\text { coef }[n] P_{\text {surplus }}[n], & P_{\text {required }}[n] \geqslant P_{\text {surplus }}[n] \\ \text { coef }[n] P_{\text {required }}[n], & P_{\text {required }}[n]<P_{\text {surplus }}[n]\end{cases}$

where the PV surplus power, $P_{\text {surplus }}$ is as follows:

$P_{\text {surplus }}[n]=\left|P_{\text {load }}[n]-P_{p v}[n]\right|$

Power required to complete battery's charge $\left(P_{\text {required }}\right)$ is as follows:

$P_{\text {required }}[n]= \begin{cases}0, & S o C[n] \geqslant S o C_{\max } \\ \frac{V_{d c} C\left|S o C[n]-S o C_{\max }\right|}{\Delta t}, & S o C_{u p} \leqslant S o C[n]<S o C_{\max } \\ \frac{V_{d c} C\left|S o C[n]-S o C_{u p}\right|}{\Delta t}, & S o C[n]<S o C_{u p}\end{cases}$

where the state of charge $S o C$ must be among $0 \leqslant S o C[n] \leqslant 1$.

The battery is charged up to $S o C_{u p}$ (upper limit of the state of charge), and it will continue charging from that point until the maximum state of charge $S o C_{\max }$ but with less power to avoid over-charging the battery. $S o C_{u p} \leqslant S o C_{\max }$

$\Delta t$ is the time interval in which the data are analysed. For example, if $n$ is recorded every minute, then $\Delta t$ will be $1 / 60 . \Delta t$ is expressed in hours, and it is between $0<\Delta t \leqslant 1$.

$V_{d c}(\mathrm{~V})$ is the nominal voltage of the battery bank, and $C$ (Ah) is the nominal capacity. The battery capacity is governed by $C$-rate (A). A $C$ rate is a measure of the rate at which a battery is discharged relative to its maximum capacity. When discharging, a battery is able to apply different capacities; a higher $C$-rate will produce a lower capacity and vice versa. $C$-rate depends on manufacturer specifications. For example, for Sonnenschein A602/625 battery (Table 2), capacities, service time, and $\mathrm{C}$-rate are as follows:

For each step $n$, the capacity $C$ will be the result of the following condition:

Table 2

C-rate when charging and discharging a Sonnenschein A602/625 battery. $C_{1}-C_{120}$.

\begin{tabular}{llllllllll}
\hline$C_{i}(\mathrm{Ah})$ & 275 & 369 & 410 & 455 & 523 & 565 & 604 & 606 & 623 \\
time $_{i}(\mathrm{~h})$ & 1 & 3 & 5 & 10 & 24 & 48 & 72 & 100 & 120 \\
C-rate $_{i}(\mathrm{~A})$ & 275 & 123 & 82 & 45.5 & 21.8 & 11.8 & 8.4 & 6.1 & 5.2 \\
\hline
\end{tabular}


$C_{-r a t e_{i}} \approx \frac{P_{b a t}^{*}[n]}{V_{d c}}$

The charge coefficient, coef, represents the gradual reduction of $P_{b a t}^{*}$ to avoid over-charging. In this model, the $P_{b a t}^{*}$ in charge has a negative value, thus the coef is between -1 and 0 .

$\operatorname{coef}[n]= \begin{cases}0.5\left(\frac{S o C[n]-S o C_{u p}}{S o C_{\max }-S o C_{u p}}-1\right), & S o C_{u p} \leqslant S o C[n] \leqslant S o C_{\max } \\ -1, & S o C[n]<S o C_{u p}\end{cases}$

\subsection{Battery discharge}

The battery is discharged when $P_{\text {load }}[n]>P_{p v}[n]$. Then, the battery power $P_{b a t}^{*}$ is as follows:

$P_{b a t}^{*}[n]= \begin{cases}P_{\text {surplus }}[n], & P_{\text {remaining }}[n] \geqslant P_{\text {surplus }}[n]-P_{\max } \\ P_{\text {remaining }}[n], & P_{\text {remaining }}[n]<P_{\text {surplus }}[n]-P_{\max }\end{cases}$

Besides, the battery will never be discharged, $P_{b a t}^{*}[n]=0$, if at least one of the following conditions is met:

$P_{\max }>P_{\text {surplus }}[n]$, or $\left[\left(\operatorname{SoC}_{\min } \leqslant \operatorname{SoC}[n] \leqslant S o C_{\text {low }}\right) \& \Delta S o C \geqslant\right.$

0], or $\operatorname{SoC}[n]<S_{\text {min }}$

The maximum power, $P_{\max }$, or curtailed power, is a specific variable of strategy $2,\left(P_{\max }>0\right)$, which determines the maximum power imported from the grid.

The battery will be allowed to discharge until the minimum state of charge $S o C_{\text {min }}$, and only when $S o C$ overcomes the $S o C_{l o w}$ level, it will be possible to discharge the battery again (thereby setting a level of hysteresis $0 \leqslant S o C_{\min } \leqslant S o C_{\text {low }}$ ).

$\triangle S o C$ is the difference between the present $S o C[n]$ and previous SoC $[n-1]$.

$\Delta \mathrm{SoC}=\operatorname{SoC}[n]-\operatorname{SoC}[n-1]$

Finally, $P_{\text {remaining }}$ is the power that can be extracted from the battery:

$P_{\text {remaining }}[n]=\frac{V_{d c} C\left|S o C[n]-S o C_{\min }\right|}{\Delta t}$

\subsection{Losses in the battery inverter}

In the previous sections $P_{b a t}^{*}$ is obtained in both charge (negative) and discharge (positive) regimes. In all cases, the absolute value of $P_{b a t}^{*}$ must not exceed the nominal power of the inverter, $\left|P_{b a t}^{*}[n]\right| \leqslant P_{\text {inverter }}$.

Considering the losses caused by the inverter, a new $P_{\text {bat }}$ is calculated by the following polynomial expression based on the three characteristic efficiency coefficients of the inverter, in both charge $\left(k_{\mathrm{c} 0}, k_{\mathrm{c} 1}\right.$, $\left.k_{\mathrm{c} 2}\right)$ and discharge $\left(k_{\mathrm{d} 0}, k_{\mathrm{d} 1}, k_{\mathrm{d} 2}\right)$ [47].

$P_{b a t}[n]=-P_{\text {inwerter }}\left(\frac{-\left(1+k_{\mathrm{c} 1}\right)+\sqrt{\left(1+k_{\mathrm{c} 1}\right)^{2}-4 k_{\mathrm{c} 2}\left(k_{\mathrm{c} 0}-\frac{\left|P_{\text {bat }}^{*}[n]\right|}{P_{\text {inverter }}}\right)}}{2 k_{\mathrm{c} 2}}\right), \quad \forall$

$$
\frac{\left|P_{\text {bat }}^{*}[n]\right|}{P_{\text {inverier }}}>k_{\mathrm{c} 0}
$$

$P_{\text {bat }}[n]=P_{\text {inverter }}\left(\frac{-\left(1+k_{\mathrm{d} 1}\right)+\sqrt{\left(1+k_{\mathrm{d} 1}\right)^{2}-4 k_{\mathrm{d} 2}\left(k_{\mathrm{d} 0}-\frac{P_{\text {bat }}^{*}[n] \mid}{P_{\text {inverter }}}\right)}}{2 k_{\mathrm{d} 2}}\right), \quad \forall$

$$
\frac{\left|P_{b a t}^{*}[n]\right|}{P_{\text {inverter }}}>k_{\mathrm{d} 0}
$$

The losses in $L$ the battery inverter, for both charge and discharge, are calculated as follows:
$L_{\text {charge }}=\sum_{n=1}^{m} \frac{P_{b a t_{n}}^{*}-P_{b a t_{n}}}{P_{b a t_{n}}^{*}}, \quad \forall P_{b a t}^{*}[n]<0$

$L_{\text {discharge }}=\sum_{n=1}^{m} \frac{P_{b a t_{n}}^{*}-P_{b a t_{n}}}{P_{b a t_{n}}^{*}}, \forall P_{b a t}^{*}[n]>0$

\subsection{Next state of charge}

The next state of charge, $\operatorname{SoC}[n+1]$, is calculated as follows:

$\operatorname{SoC}[n+1]=\frac{V_{d c} C S o C[n]-\Delta t P_{b a t}[n]}{V_{d c} C}$

\subsection{Imported and exported grid power}

The grid power, $P_{\text {grid }}$ is calculated by the following expression:

$P_{\text {grid }}[n]=P_{\text {load }}[n]-P_{p v}[n]-P_{b a t}[n]$

$P_{g r i d}$ will automatically have a positive value when it is imported from the grid and will be negative when it is exported to the grid.

Finally, the accumulated power of $P_{p v}, P_{\text {load }}, P_{\text {bat }}$ and $P_{\text {grid }}$ can be expressed in terms of energy $(E)$ in $\mathrm{kWh}$ for a certain period of time in the following way:

$E_{p v}=0.001 \Delta t \sum_{n=1}^{m} P_{p v_{n}}$

$E_{\text {load }}=0.001 \Delta t \sum_{n=1}^{m} P_{\text {load }_{n}}$

$E_{\text {charge }}=0.001 \Delta t \sum_{n=1}^{m} P_{b a t_{n}}, \quad \forall P_{b a t}[n]<0$

$E_{\text {discharge }}=0.001 \Delta t \sum_{n=1}^{m} P_{b a t_{n}}, \quad \forall P_{b a t}[n]>0$

$E_{\text {exported }}=0.001 \Delta t \sum_{n=1}^{m} P_{\text {grid }_{n}}, \quad \forall P_{\text {grid }}[n]<0$

$E_{\text {imported }}=0.001 \Delta t \sum_{n=1}^{m} P_{\text {grid }}, \quad \forall P_{\text {grid }}[n]>0$

where $m$ is the total number of data available. For example, for a value per minute $(\Delta t=1 / 60)$ over a period of $24 \mathrm{~h}, m=24 / \Delta t=1440$.

\subsection{Self-sufficiency and self-consumption}

The amount of PV energy locally consumed is called absolute selfconsumption when it is instantaneously supplying the electrical demand consumption. However, this value can be expressed relative to the total consumption 'self-sufficiency parameter', or to the total generation 'self-consumption parameter' [48].

In the particular case of HVAC demand, the supply can come from two sources: PV (directly or indirectly through the battery) and the grid. The percentage of demand supplied from PV is the self-sufficiency $\left(\varepsilon_{s s}\right)$ of the system. Likewise, the energy produced by the PV system can have $E_{\text {load }}$ three destinations: HVAC, the battery, and the grid. Of the total PV generation, the percentage of energy directed toward both battery and HVAC is the self-consumption $\left(\varepsilon_{s c}\right)$ of the system. Therefore, the expressions to calculate self-sufficiency and self-consumption for a PV hybrid system are as follows:

$\varepsilon_{\text {ss }}=\frac{E_{\text {load }}-E_{\text {imported }}}{E_{\text {load }}} 100 \%$ 
$\varepsilon_{s c}=\frac{E_{p v}-E_{\text {exported }}}{E_{p v}} 100 \%$

\subsection{Loss-of load (LoL)}

In the case of using strategy $2\left(P_{\max }>0\right)$, a method to quantify $L o L$ is presented in this paper, which indicates the percentage of energy of that will not be supplied either by $E_{p v}$ or by $E_{\text {discharged }}$ or by $E_{\text {imported }}$. This occurs when $P_{p v}=0, S o C \leqslant S o C_{\min }$ and principally due to the contracted power restriction in which $P_{\text {grid }}$ should not be higher than $P_{\max }$.

$L o L=\frac{E_{L o L}}{E_{\text {load }}} 100 \%$

where

$E_{L o L}=0.001 \Delta t \sum_{n=1}^{m} P_{L o L_{n}}$

$P_{L o L}[n]=P_{\text {grid }}[n]-\min \left\{P_{\text {grid }}[n], P_{\max }\right\}, \quad \forall P_{\text {grid }}[n]>0$

\subsection{Experimental validation}

The proposed model has been implemented in MATLAB ${ }^{\oplus}$ and confirmed with experimental data obtained from the measuring and control equipment. As an example of the experimental validation, the results of a typical winter day (January 25, 2017) are shown in Fig. 8.

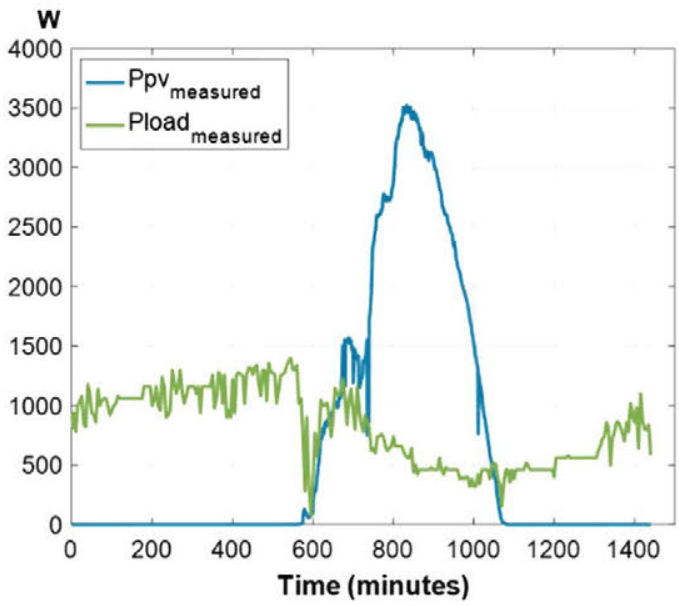

(a)

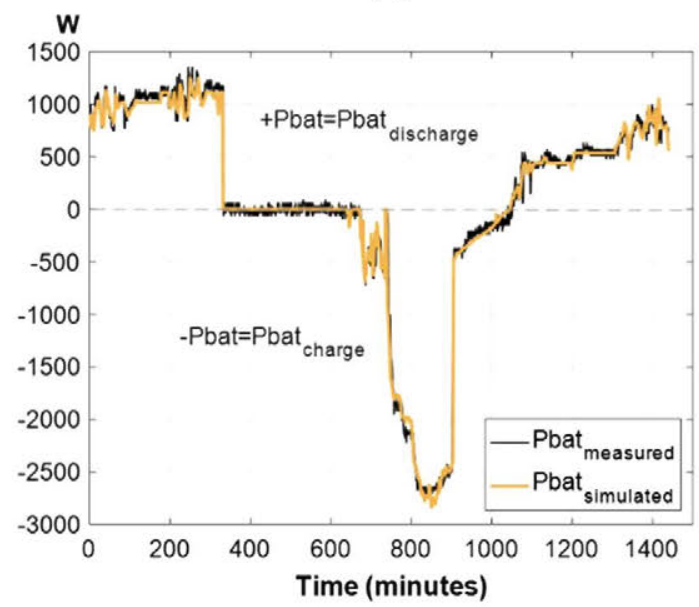

(c)
The system has been configured with the following parameters:

Strategy: $1 ; \quad S o C[1]=0.78 ; \quad S o C_{\max }=1 ; \quad S o C_{u p}=0.85$; $S o C_{\text {low }}=0.45 ; S o C_{\min }=0.40$.

To validate strategy 2, results of February 15, 2017 are shown in Fig. 9. In this case, the system has been configured with the following parameters:

Strategy: $\quad 2 ; \quad S o C[1]=0.92 ; \quad S o C_{\max }=1 ; \quad S o C_{u p}=0.85 ;$ $S o C_{\text {low }}=0.45 ; S o C_{\min }=0.40 ; P_{\max }=805 \mathrm{~W}$.

In addition to the specific days presented in Fig. 8 and Fig. 9, 44-day experimental measurements $(63,360$ one-minute samples) between January and June 2017 have been carried out. In Fig. 10, the determination coefficients $\left(\mathrm{R}^{2}\right)$ that show the quality of the model in order to replicate the SoC, $P_{\text {grid }}$ and $P_{b a t}$, are shown.

There are numerous formulas to determine the error between the measured values and the simulated values. However, in this study, Mean Absolute Error (MAE) and Symmetric Mean Absolute Percentage Error (SMAPE) have been considered to quantify the error of the proposed model (Table 3 ) in absolute and relative terms respectively.

MAE takes the absolute value of errors (measured value minus simulated value) and averages them over the entirety of the forecast time periods. Taking an absolute value of a number disregards whether the number is negative or positive and, in this case, avoids the positives and negatives cancelling each other out. SMAPE is an accuracy measure based on percentage (or relative) errors. The absolute difference between the measured value and the simulated value is divided by half the sum of measured value and the simulated value. The value of this

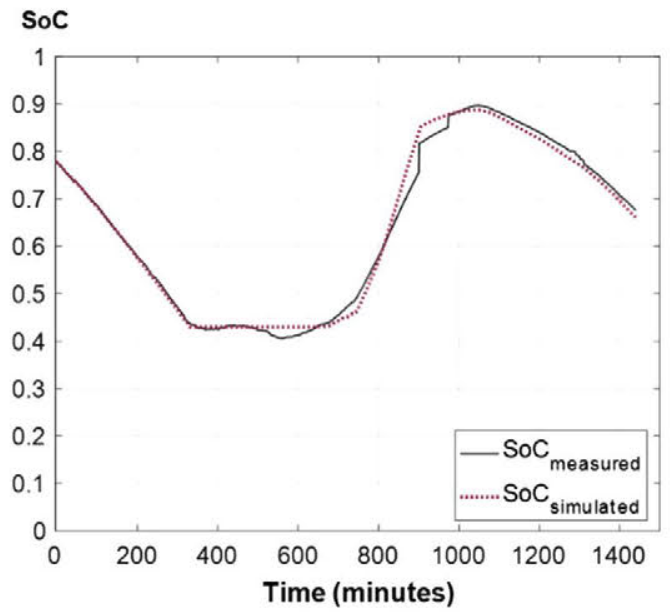

(b)

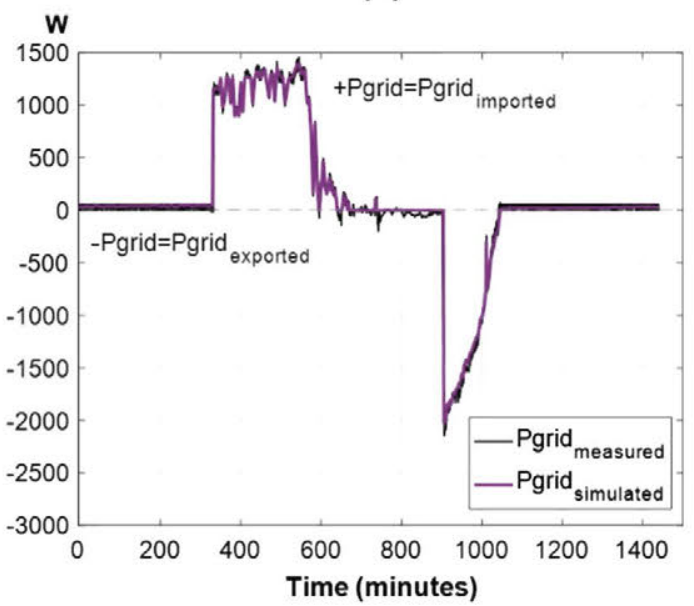

(d)

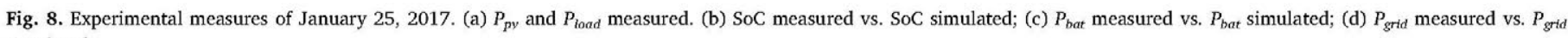
simulated. 


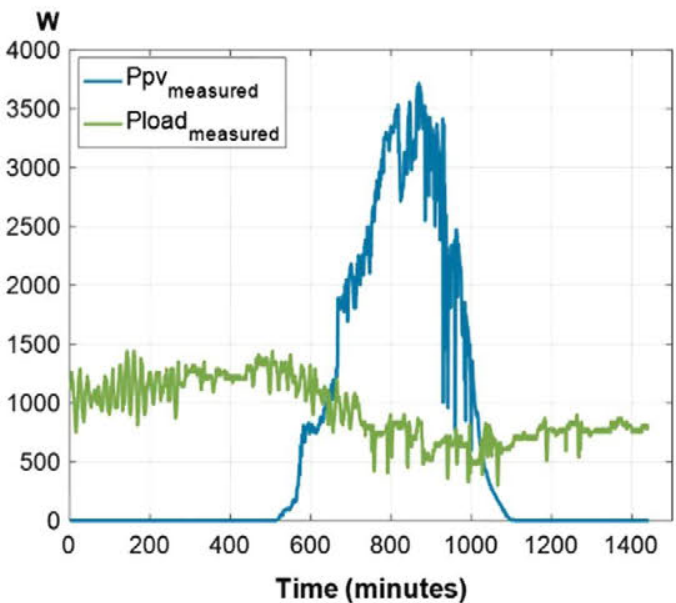

(a)

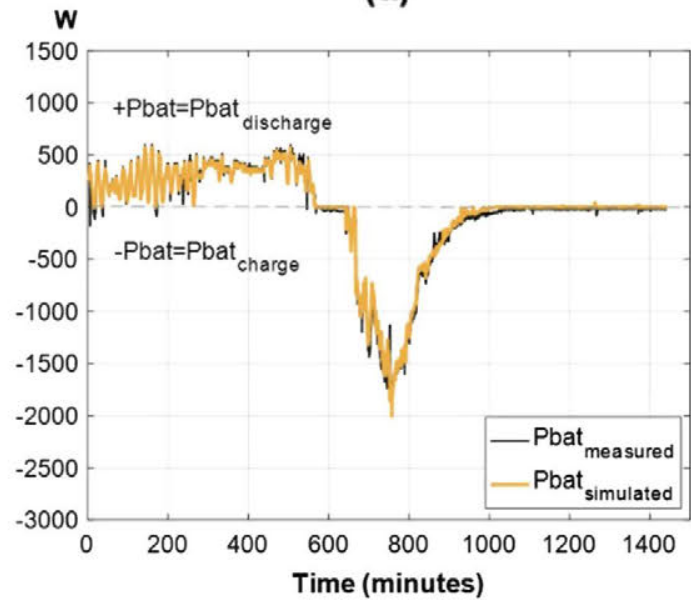

(c)

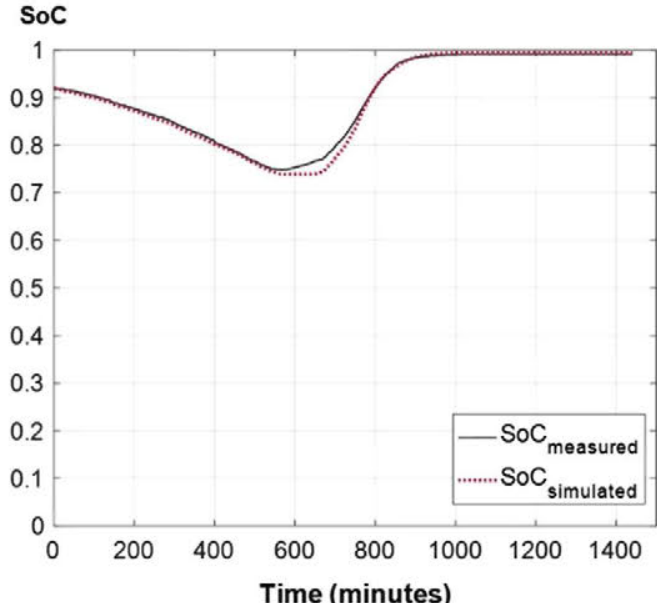

(b)

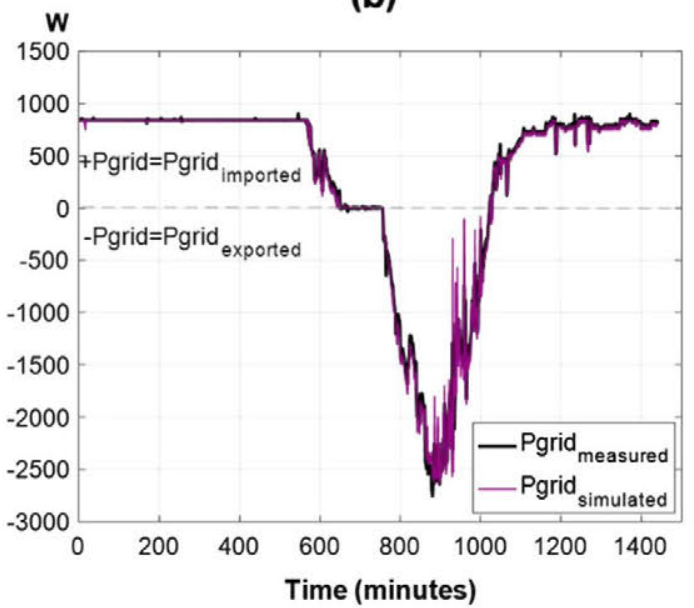

(d)

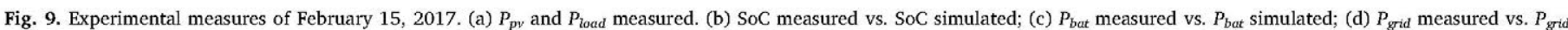
simulated.

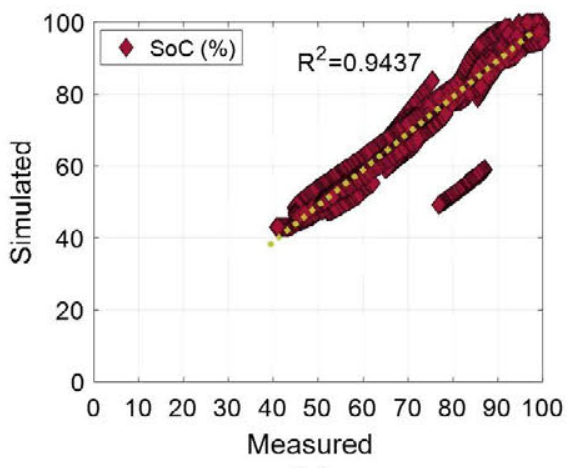

(a)

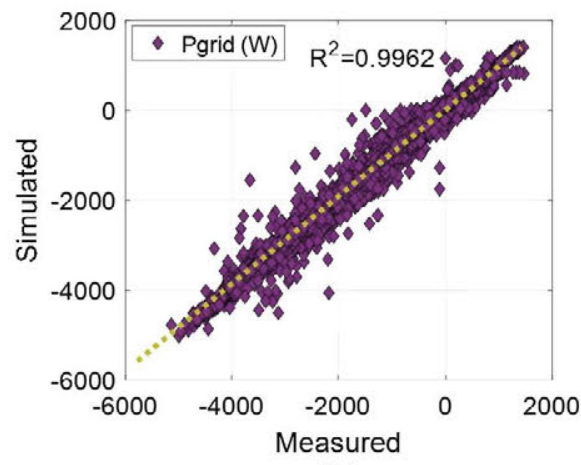

(b)

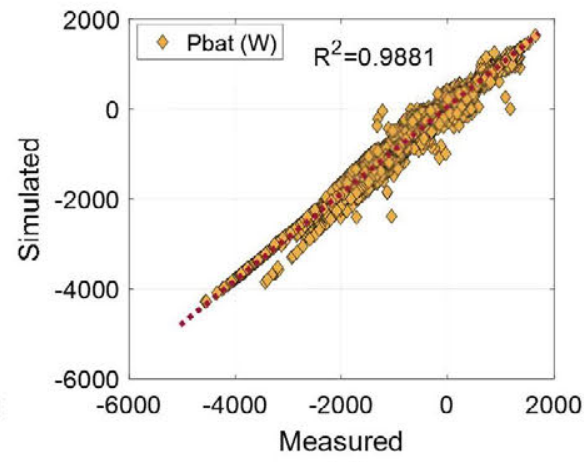

(c)

Fig. 10. Measured data versus simulated data during 44-day experimental campaign. 63,360 one-minute samples for (a) SoC, (b) $P_{g r i d}$ and (c) $P_{b a t}$.

calculation is summed for every point and divided again by the total number of points.

\section{Case study: technical analysis}

In this section, the technical analysis of a specific case study is presented. The electrical consumption of HVAC is established using experimental data. Particular sizes of both PV system and BESS are used in order to simulate the behaviour of the grid-connected PV hybrid system, using the model presented in Section 4.

\subsection{Annual HVAC load estimation}

In order to estimate the annual thermal loads of the building and the associated electricity demand of the HVAC system, an extensive measuring campaign has been conducted to measure the HVAC electrical consumption and to monitor thermal comfort conditions inside the building to assess whether it meets internationally accepted standards.

In this work, two thermal comfort methods described in [49] (see Fig. 11) have been analysed: Fanger's PMV method and Adaptive Comfort method. 
Table 3

Error calculation (on a per-minute basis) of 44-day experimental measurements.

\begin{tabular}{lll}
\hline \multirow{2}{*}{ Variable } & \multicolumn{2}{l}{ Error } \\
\cline { 2 - 3 } & MAE & SMAPE \\
\hline SoC & $1.10 \%$ & $0.34 \%$ \\
$P_{\text {bat }}$ & $34.51 \mathrm{~W}$ & $5.23 \%$ \\
$P_{\text {grid }}$ & $44.76 \mathrm{~W}$ & $4.04 \%$ \\
$E_{\text {charge }}$ & $13.90 \mathrm{kWh}$ & $2.40 \%$ \\
$E_{\text {discharge }}$ & $6.04 \mathrm{kWh}$ & $1.10 \%$ \\
$E_{\text {eqported }}$ & $6.39 \mathrm{kWh}$ & $0.27 \%$ \\
$E_{\text {imported }}$ & $14.61 \mathrm{kWh}$ & $2.62 \%$ \\
\hline
\end{tabular}

- The Fanger's PMV method is a heat balance model that views the human being as a passive recipient of thermal stimuli. The resulting Predicted Mean Vote Index (PMV) is calculated with the Fanger's equation [50] and widely used with international standards ISO 7730 [51]. Thus, variables such as clothing, physical activity, $\mathrm{CO}_{2}$ concentration, relative humidity, outdoor and indoor temperature among others are involved in this method.

- The adaptive comfort model assumes that humans consciously or unconsciously modify their behaviour to adapt to thermal conditions. Therefore, the thermal balance equations cannot be strictly applied because the thermal adaptation is, by nature, a dynamic process [52]. The adaptive comfort formula does not directly take into account the classical comfort factors described above but simply establishes the indoor comfort temperature as a function of outdoor temperature $[53,54]$.

Heat pumps have been configured to operate automatically at the following setpoint temperatures: $20^{\circ} \mathrm{C}$ for months October to March, and $26^{\circ} \mathrm{C}$ for months April to September. In total, 90,720 one-minute samples have been collected, covering the period February-November 2016.

According to the Fanger's method (see Fig. 11a), 100\% of the samples are within Category C; similarly, $98 \%$ of samples are within Category B limits; $58 \%$ are within Category A. Furthermore, according to the Adaptive model (see Fig. 11b), $96 \%$ of the samples are within Category II); likewise, $82 \%$ of samples are within Category I limits.

Once comfort conditions have been guaranteed inside the house, the heat pump's electrical consumption $\left(P_{\text {load }}\right)$ is estimated - see Eq. (26) - depending on the main variables monitored: $T_{\text {outdoor }}$ : outdoor temperature $\left({ }^{\circ} \mathrm{C}\right) ; T_{\text {indoor }}$ : indoor temperature $\left({ }^{\circ} \mathrm{C}\right) ; G_{h r z}$ : global horizontal irradiation $\left(\mathrm{W} / \mathrm{m}^{2}\right)$; and $h$ : hour (from 1 to 24$)$.

Although the above variables have been monitored, in this first study a linear regression model was used to estimate $P_{\text {load }}$ because it

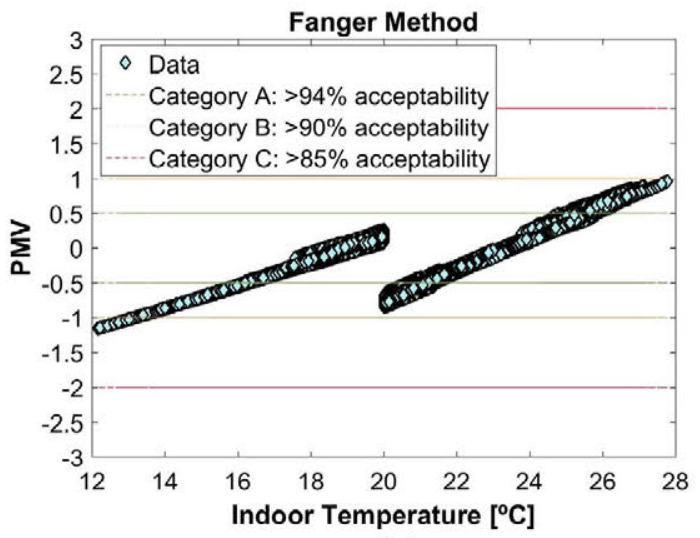

(a)
Table 4

(a) Coefficients $a_{x}$ of Eq. (26) and the corresponding p-value. (b) F-statistic parameter of regression model used.

\begin{tabular}{|c|c|c|c|c|c|}
\hline \multicolumn{2}{|l|}{ Winter } & \multicolumn{2}{|c|}{ Spring/Autumn } & \multicolumn{2}{|l|}{ Summer } \\
\hline$a_{x}$ & p-value & $a_{x}$ & p-value & $a_{x}$ & p-value \\
\hline 6312.50 & $2.32 \mathrm{E}-131$ & -4346.00 & $2.67 \mathrm{E}-50$ & 3827.58 & 0.00 \\
\hline 134.77 & $2.18 \mathrm{E}-29$ & -188.69 & $2.79 \mathrm{E}-271$ & -328.16 & 0.00 \\
\hline-629.19 & $8.34 \mathrm{E}-91$ & 508.47 & $1.28 \mathrm{E}-55$ & -108.80 & $1.79 \mathrm{E}-128$ \\
\hline 0.87 & $1.70 \mathrm{E}-19$ & 2.42 & $2.08 \mathrm{E}-83$ & 1.97 & 0.00 \\
\hline-21.20 & $1.64 \mathrm{E}-07$ & 69.04 & $2.74 \mathrm{E}-91$ & -28.27 & $2.51 E-19$ \\
\hline-10.80 & $3.25 E-48$ & 4.42 & $6.72 \mathrm{E}-44$ & 8.76 & 0.00 \\
\hline $9.25 E-3$ & $1.05 E-03$ & $3.89 \mathrm{E}-02$ & $4.79 E-216$ & $-4.46 \mathrm{E}-02$ & 0.00 \\
\hline-0.35 & $5.46 \mathrm{E}-05$ & $1.11 \mathrm{E}-02$ & $0.73^{*}$ & 1.91 & 0.00 \\
\hline $5.82 \mathrm{E}-3$ & $0.34^{*}$ & $8.54 \mathrm{E}-02$ & $6.50 \mathrm{E}-31$ & $-4.73 \mathrm{E}-02$ & $6.90 \mathrm{E}-74$ \\
\hline 1.11 & $1.43 \mathrm{E}-06$ & -3.12 & $1.84 \mathrm{E}-67$ & -1.28 & $2.97 \mathrm{E}-18$ \\
\hline$-7.18 \mathrm{E}-2$ & $1.11 \mathrm{E}-168$ & -0.015 & $4.75 E-12$ & $1.53 \mathrm{E}-02$ & $1.40 \mathrm{E}-67$ \\
\hline 1.34 & $1.14 \mathrm{E}-11$ & 3.32 & 0.00 & 2.70 & 0.00 \\
\hline 18.87 & $2.95 \mathrm{E}-89$ & -12.19 & $3.54 \mathrm{E}-41$ & 0.26 & $1.87 \mathrm{E}-02$ \\
\hline$-1.91 \mathrm{E}-04$ & $4.56 \mathrm{E}-13$ & $9.07 \mathrm{E}-05$ & $3.43 E-04$ & $-3.29 \mathrm{E}-05$ & $1.79 \mathrm{E}-04$ \\
\hline-0.28 & $6.24 \mathrm{E}-11$ & $22.84 \mathrm{E}-02$ & $2.55 E-42$ & 0.78 & $1.35 E-184$ \\
\hline
\end{tabular}

(b)

\begin{tabular}{lll}
\hline & F-statistic vs. constant model & p-value \\
\hline Winter & $3.23 \mathrm{E}+03$ & 0.00 \\
Spring/Autumn & $2.08 \mathrm{E}+03$ & 0.00 \\
Summer & $2.12 \mathrm{E}+04$ & 0.00 \\
\hline
\end{tabular}

* Coefficients $a_{x}$ with p-value higher than 0.05 can be ignored because of poor correlation.

presents better adjustments compared to other existing simulation tools. However, other methods can be used, such as Model Predictive Control (MPC) $[55,56]$ in order to obtain $P_{\text {load }}$. Additionally, MPC, together with forecasting of PV generation [34] and the battery control strategies presented in this paper, could be carried out in future research.

$$
\begin{aligned}
P_{\text {load }}= & a_{0}+a_{1} T_{\text {outdoor }}+a_{2} T_{\text {indoor }}+a_{3} G_{\text {hrz }}+a_{4} h+a_{5} T_{\text {outdoor }} T_{\text {indoor }} \\
& +a_{6} T_{\text {outdoor }} G_{\text {hrz }}+a_{7} T_{\text {outdoor }} h+a_{8} T_{\text {indoor }} G_{\text {hrz }}+a_{9} T_{\text {indoor }} h \\
& +a_{10} G_{\text {hrz }} h+a_{11} T_{\text {outdoor }}^{2}+a_{12} T_{\text {indoor }}^{2}+a_{13} G_{h r z}^{2}+a_{14} h^{2}
\end{aligned}
$$

where coefficients $a_{x}$ vary depending on the season of the year. In Table 4(a), values of the coefficients and the associated p-values are reported for all seasons. As it can be noted, all the values are lower than the common statistical significance level of 0.05 with the exception of two values marked with an asterisk.

A low p-value $(<0.05)$ in Table $4(a)$ indicates that the $a_{x}$ has a

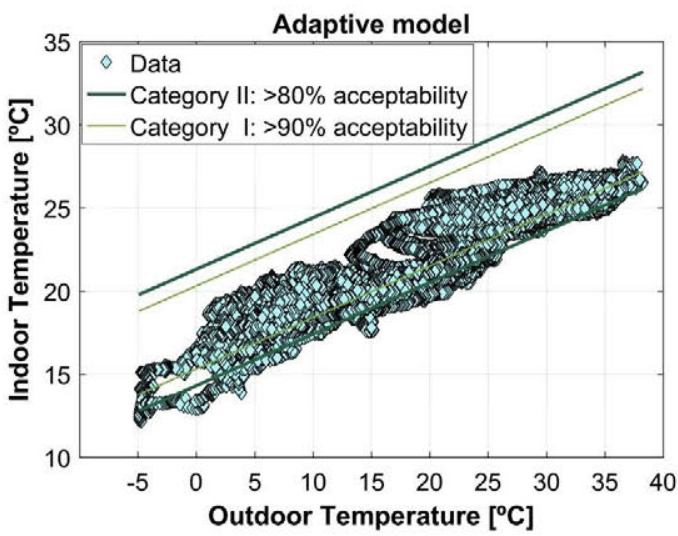

(b)

Fig. 11. Evaluation of thermal comfort methods: (a) Fanger Method, and (b) adaptive model. 
meaningful addition to the model since changes in the predictor's value are related to changes in the response variable. On the contrary, a pvalue greater than the common level of 0.05 suggests that changes in the predictor are not associated with changes in the response. Moreover, the F-statistics of the regression model fit versus the constant model showed in Table 4(b) have a p-value lower than the statistical significance level of 0.05 , which indicates that the regression model provides a better fit than the intercept-only model.

The output of the simulation was compared to the experimentally measured data (as mentioned above, minute samples over 9 months covering all seasons of the year) in order to obtain a feedback on the reliability and accuracy of the model. The R-squared value of 0.8612 means that the model explains about $86 \%$ of the variability in the response, showing a reasonably good agreement between the proposed linear-regression model and measured $P_{\text {load }}$, as it can be seen in Fig. 12.

Based on the regression model above, annual HVAC electricity demand with a minute-based resolution has been simulated, as shown in Fig. 13a. Annual accumulated energy for this demand is as follows: $E_{\text {load }}=3807 \mathrm{kWh}$.

In the specific case study, the simulation was performed with $P_{\max }=805 \mathrm{~W}$. Nevertheless, it is not the only possible value that can be used. In fact, in Spain, customers can choose different contracted power levels with the utility grid [57]. In this sense, any value higher than $P_{\max }$ is considered as a peak-load. According to the values in Fig. 13a, in some cases, the demand exceeds $2300 \mathrm{~W}$. Therefore, if a PV-battery system is not used, the contracted power by the user should be at least $3450 \mathrm{~W}$ (see Table 5). In the same Fig. 13a, seasonal periods with consumption peaks (winter and summer) can be identified. Consequently, it is reasonable to use strategy 2 (grid-peak shaving) in those periods. In order to determine the new contracted power, several simulations using Eq. (23) were performed with $P_{m a x}$ values lower than $3450 \mathrm{~W}$. Table 5 shows that for $P_{\max }=805 \mathrm{~W}$, the $L o L$ rate is $1.70 \%$, i.e. $65 \mathrm{kWh}$ of the annual HVAC consumption would not be supplied by the PV hybrid system. This value has a low impact on the comfort conditions of the building, as previously indicated in Fig. 11. As $P_{\max }$ decreases, it increases self-sufficiency as well. However, it will also drastically increase the $L o L$ rate, resulting in unsatisfying comfort conditions.

\subsection{Annual PV generation}

Annual simulation of the PV system's electrical production has been carried out according to the characteristics given in Section 2.2.2 using validated tools and procedures [35] for the determination of the solar potential, which includes the effect of shadows and consideration of losses (optical and thermal losses in the generator, voltage drops, conversion losses in the inverter, etc.).

Due to the fact that the HVAC consumption in buildings is, in general, just a part of the total load and the objective of this study is the assessment of the potential of PV hybrid systems to cover HVAC loads, specific PV arrays from the building demonstrator have been selected (arrays 3\&4 from Table 1) so that annual expected PV generation (Fig. 13b) is $E_{p v}=3548 \mathrm{kWh}$, comparable to the annual HVAC consumption $\left(E_{p v} \approx E_{\text {load }}\right)$.

\subsection{Battery capacity}

The case study is simulated with a lead-acid battery bank coupled to the AC bus by means of a bidirectional inverter. According to [18], the optimal nominal storage size for residential buildings using PV systems was about $4.5 \mathrm{kWh}$ in 2013 , and it will be increasing significantly to $7 \mathrm{kWh}$ in 2021 under different scenarios of electricity costs. In this work, the value of $6 \mathrm{kWh}\left(C_{10}=125 \mathrm{Ah}, V_{d c}=48 \mathrm{~V}\right)$ widely used and tested [58] will be simulated along with variations between 0 and $10 \mathrm{kWh}$ for further sensitivity analysis. In addition, $60 \%$ of depth of discharge $\left(S o C_{\min }=0.4\right)$ has been established, which is the value

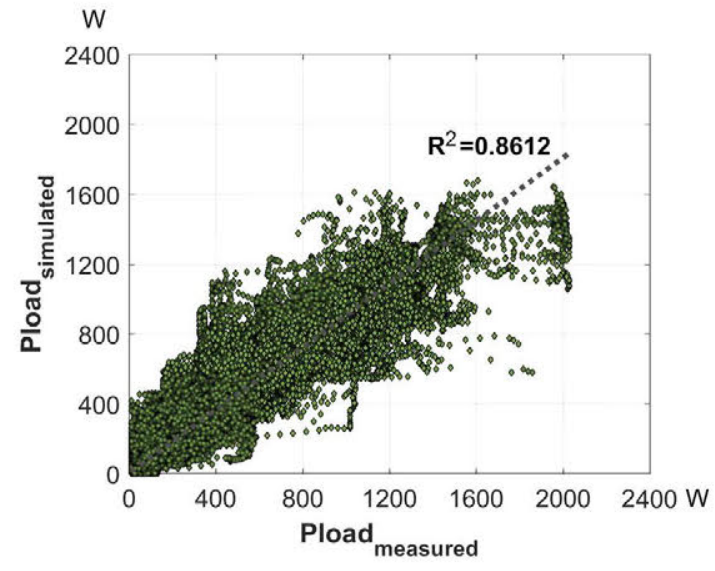

Fig. 12. Simulated and measured electricity demand for HVAC $\left(P_{l o a d}\right)$.

recommended by the manufacturer to extend the lifetime of the batteries and to avoid over-discharge stress.

\subsection{Annual power flows}

Due to the considerable number of input variables, a specific case has been chosen to show the overall behaviour of PV hybrid system over one year based on the parameters of the following sections:

- Location: Madrid

- PV generator nominal power: $2.68 \mathrm{~kW}_{\mathrm{p}}$

- Orientation and tilt angle: South, $25^{\circ}$

- BESS nominal capacity: $6 \mathrm{kWh}\left(V_{d c}=48 \mathrm{~V} ; C_{10}=125 \mathrm{Ah}\right)$

- $S o C_{\min }=0.40 ; S o C_{\text {low }}=0.45 ; S o C_{u p}=0.95 ; S o C_{\max }=1$

- Control strategies: strategy 2 in winter/summer; strategy 1 in spring/autumn.

The simulation of both $P_{\text {grid }}$ and $P_{b a t}$ are shown in Fig. 14a, and SoC is shown in Fig. 14b. In winter and summer months (from day 1 to 90 , 181 to 243 and 334 to 365 ), the battery is discharged to supply power values higher than $P_{\max }=805 \mathrm{~W}$ (strategy 2 ). For the rest of the year, $P_{\text {load }}$ does not exceed the $P_{\max }$. Therefore, the battery control strategy 1 is used to reduce energy consumption from the grid.

\subsection{Grid demand duration curve}

The grid load duration curves are shown in Fig. 15, which represent the grid electricity demand to supply the HVAC load in three different scenarios: the first one $\left(b_{l u e^{2}}\right.$ ) is without using PV or battery; the second curve (red) shows the case of using only PV (no BESS); the third curve (yellow) using PV and BESS.

Using the PV system alone to directly supply the HVAC demand only reaches $27 \%$, i.e. $73 \%$ of energy comes from the grid. When the BESS is added, the energy from grid can be reduced to $54 \%$, as observed in Fig. 15.

\subsection{Self-sufficiency \& self-consumption}

The amount of PV energy locally consumed is called absolute selfconsumption when it is instantaneously supplying the electrical demand consumption. However, this value (expressed as a percentage) can be relative to the total generation (self-consumption) or to the total consumption (self-sufficiency). Necessary energy to supply the HVAC demand comes from two sources: PV (directly or indirectly, through the

\footnotetext{
${ }^{2}$ For interpretation of color in Figs. 15 and 16, the reader is referred to the web version of this article.
} 


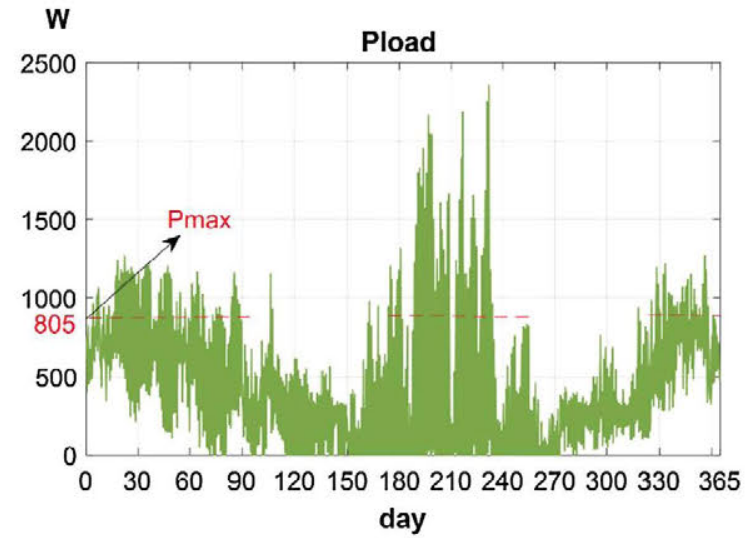

(a)

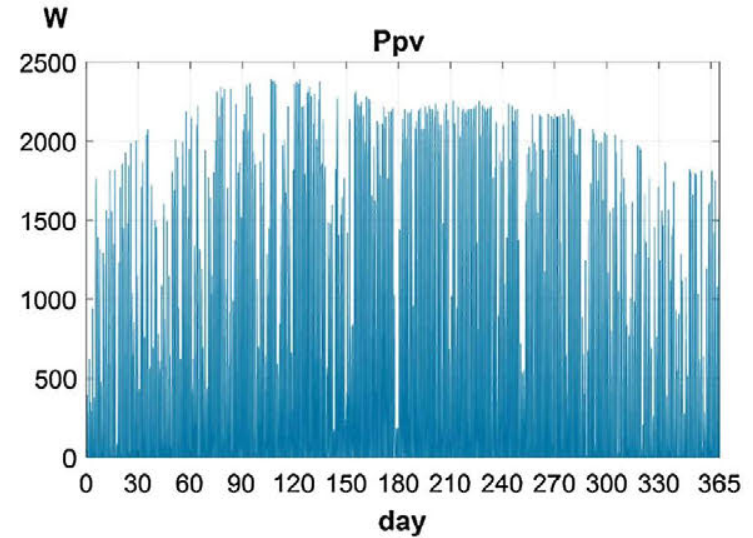

(b)

Fig. 13. (a) Annual HVAC consumption; (b) annual PV energy generation.

Table 5

Results of $L O L$ and self-sufficiency parameters using combining of control strategies based on standard powers for single-phase distribution systems in Spain.

\begin{tabular}{llll}
\hline$P_{\max }(\mathrm{W})$ & Reduction (\%) & LoL $(\%)$ & Self-sufficiency (\%) \\
\hline 3450 & 0.00 & 0 & 39.28 \\
2300 & 33.34 & $5 \times 10^{-4}$ & 39.28 \\
1725 & 50.00 & 0.01 & 39.41 \\
1150 & 66.67 & 0.13 & 40.35 \\
805 & 76.67 & 1.70 & 44.01 \\
690 & 80.00 & 4.19 & 45.48 \\
345 & 90.00 & 21.26 & 48.56 \\
\hline
\end{tabular}

Bold values indicate the $P_{\max }=805 \mathrm{~W}$ is used in the case study because of both its high reduction of contracted power (almost 77\%) and low impact of LoL (1.70\%).

battery) and the grid.

According to Eqs. (21) and (22), the annual values of self-sufficiency and self-consumption parameters have been calculated (see Fig. 16). Therefore, the HVAC consumption (Fig. 16a) is supplied directly by the PV (light green), the battery (dark green), or by the grid (orange).

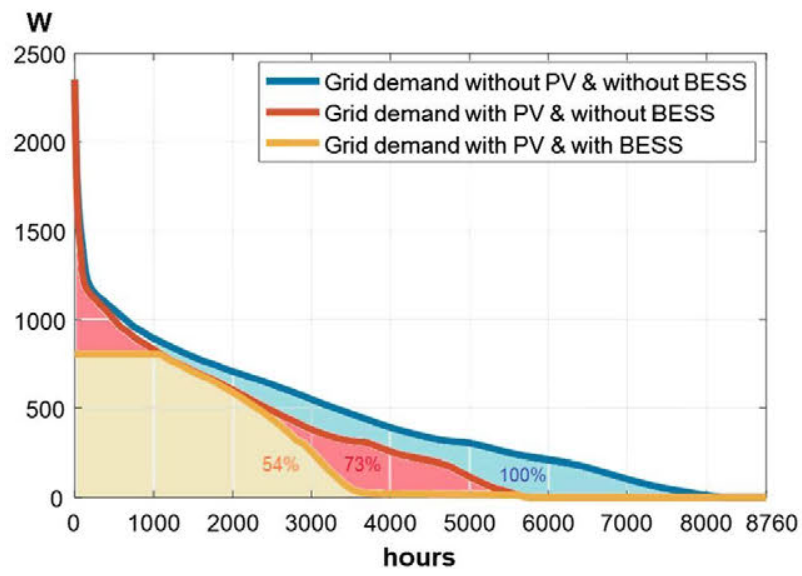

Fig. 15. Duration curve of imported energy from the grid to supply the demand for HVAC.

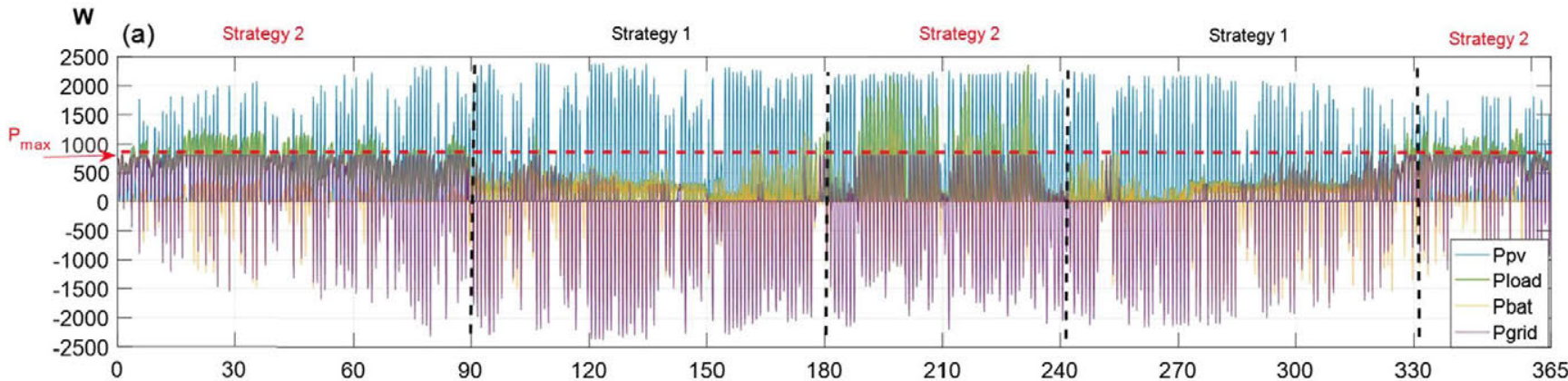

SoC (b)

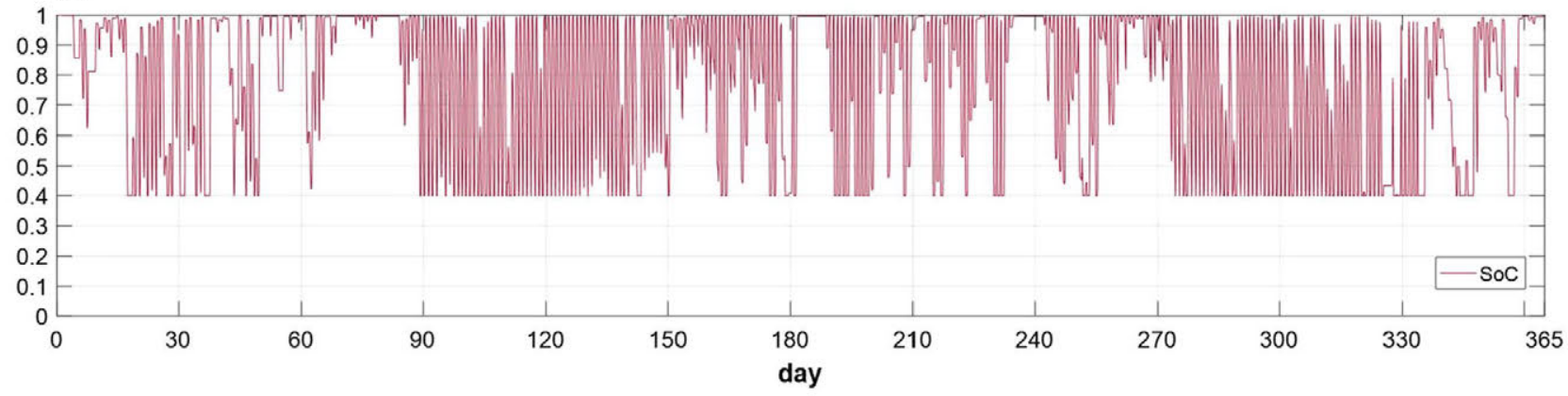

Fig. 14. (a) Annual power interaction in Magic Box. $P_{p v}$ : PV power; $P_{\text {load }}$ HVAC load; $p_{\text {bat }}$ : battery power; $p_{\text {grid }}:$ grid power. (b) SoC: battery state of charge. 
Self-sufficiency (green). Origin of power consumptions Total Demand: $\mathbf{3 8 0 7} \mathrm{kWh} /$ year

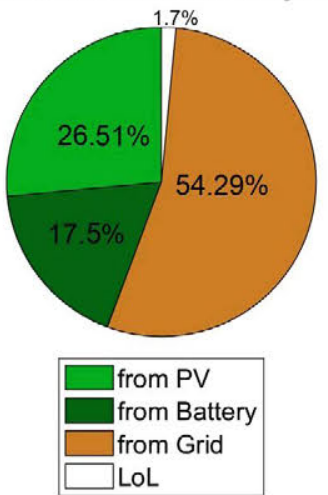

(a)
Self-consumption (green). Total PV Generation: 3548 kWh/year

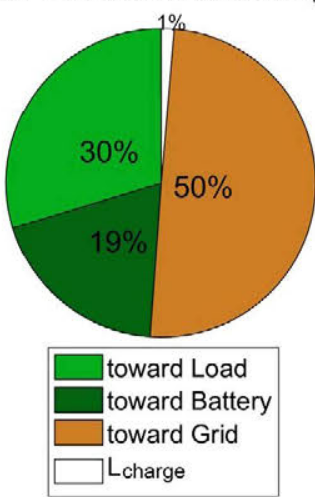

(b) Final use of PV generation:

Fig. 16. Annual energy accumulated. (a) Origin of energy consumed by HVAC and selfsufficiency; (b) final use of PV generation and self-consumption.

Likewise, the PV energy generated (Fig. 16b) flows toward the demand (light green), or to charge the battery (dark green), and finally, the PV surplus is exported to the grid (orange).

In Fig. 16a, the origin of energy to supply HVAC load is shown. The PV power supplies the HVAC load with 44\% (26.51\% directly and $17.5 \%$ indirectly through the batteries). It could be inferred that increasing the PV or BESS sizes would increase the self-sufficiency rate, but as it will be considered later in the sensitivity analysis (Section 6.4), the increase of self-sufficiency is minimal.

In Fig. 16b, the final use of electricity locally generated by the PV system is shown, in which $30 \%$ instantly covers the HVAC demand, $19 \%$ is used to charge the batteries, and $50 \%$ is exported to the grid or can be used to supply other distinct types of demand with different load profiles that will significantly increase self-consumption.

\section{Case study: economic analysis}

In any investment on grid-connected PV system, in addition to solar potential, there are many parameters that must be considered in order to determine if it is worthwhile from a financial point of view [59]. In this section, an economic analysis of the case study is presented, using three important parameters: LCOE, payback time and billing saving.

\subsection{Levelized cost of electricity ( $L C O E)$}

LCOE is one of the most important parameters in the field of PV systems economic analysis [60-62]. The LCOE is calculated by accounting for all the PV system's expected lifetime costs (including construction, financing, maintenance, and taxes), which are then divided by the whole system's lifetime expected PV energy (kWh). All cost and benefit estimates are adjusted for inflation and discount rate to account for the time-value of money. The importance of LCOE is to assess the proximity to grid parity from the perspective of the consumer, who is interested in comparing the grid electricity cost with the cost of the PV energy generated and levelized in the lifetime of the system. LCOE is calculated as shown in Eq. (27).

$L C O E=\frac{I+\sum_{t=1}^{T} \frac{C_{t}}{(1+r)^{t}}}{\sum_{t=1}^{T} \frac{E_{t}}{(1+r)^{t}}}$

where the parameters used are explained in Table 6.

\subsubsection{Lead-acid battery lifetime}

In a PV-battery system, battery lifetime is a crucial factor to determine whether the system is technically and economically feasible. In addition, the actual lifetime of a specific battery bank depends on many factors, among the most important are: the state of charge, degradation, and cycling according to the specific application and BESS strategies. Thus, annual simulations have been carried out, and the battery aging models proposed in [63], widely used by the scientific community [64-67], have been implemented.

The full cycles method defines the end of the battery lifetime when a specified number of full complete cycles (charge-discharge) are reached. The method of Ah Throughput model is based on counting the cycles corresponding to each range of the depth of discharge (specific for a battery) over a year. Finally, the Kinetic Battery Model calculates the capacity loss by corrosion and degradation. The end of battery lifetime is reached when the remaining battery capacity is $80 \%$ of its initial capacity.

In Table 7, results of the three aging models can be compared for the same case study. In the sections below, the Kinetic Battery Model proposed by Schiffer [65] is considered because it provides the most realistic assessment of aging and degradation effects on battery performance. Therefore, assuming the hypothetical PV system's lifespan expectancy is 30 years [62], it will be necessary to purchase the battery bank four times $(4 \times 7.3 \approx 30$ years).

Considering that the price of the PV systems and the batteries are constantly reduced, many simulations have been carried out to calculate the LCOE (Fig. 17) with variations of the BESS between $100 € / \mathrm{kWh}$ and $300 \mathrm{C} / \mathrm{kWh}$, and with different PV system prices between $0.5 \mathrm{C} / \mathrm{W}_{\mathrm{p}}$ and $2 € / W_{p}$, which represent the current market conditions [68].

According to [68], the installed PV system price in the residential sector for Spain is between 1.4 and $1.5 € / \mathrm{W}_{\mathrm{p}}$, including the price of modules, inverters, and the Balance of System (BoS). In this case study, $1.5 € / \mathrm{W}_{\mathrm{p}}$ is considered, assuming that the PV inverter also performs the BESS inverter function. Likewise, according to $[17,20]$, the price of batteries ranges between $150 € / \mathrm{kWh}$ and $300 € / \mathrm{kWh}$. For this case study, $243 € / \mathrm{kWh}$ is considered because it is the actual purchase price of the installed batteries. Thus, the point $(243 \mathrm{C} / \mathrm{kWh}, 1.5 \mathrm{C} / \mathrm{Wp})$ can be located in Fig. 17, which results in $0.16 € / \mathrm{kWh}$.

\subsection{Payback-time}

One of the challenges of the PV systems is its cost effectiveness, and therefore, its ability to generate profits $[69,70]$. Payback-time is the time in years when the investment begins to generate economic benefits. It is a parameter derived from the Net Present Value (NPV) that is used to evaluate the ability to make a profit.

To calculate the payback-time (Fig. 18), the annual income of the economic savings coming from the PV hybrid system is considered. In addition, three scenarios of the PV surplus value are considered: Scenario $\mathrm{A}$, where PV surplus is not valued and is exported to the grid without receiving any monetary compensation; Scenario B, where PV surplus is remunerated at the electric market price, and; Scenario C, where PV surplus is used to supply other loads into the house. Expenses correspond to the operation and maintenance and changing of equipment, where the PV inverter must be changed after 15 years, and the batteries must be replaced at the end of their lifetime.

The graphs presented in Fig. 18 are useful to evaluate any value of the payback time (expressed in years) for the established price ranges and for the mentioned scenarios of the PV surplus. For example, payback time at the point $\left(243 € / \mathrm{kWh}, 1.5 € / \mathrm{W}_{\mathrm{p}}\right)$ can be obtained in Fig. 18. Results are 26, 21, and 16 years for scenarios A, B, and C respectively.

\subsection{Billing saving}

In order to calculate the utility bill, the 2.0 DHA tariff period (residential tariff with two periods) was used, in accordance with the Spanish regulated prices currently in effect [42]. The cost in Euros that would be paid to the utility has been calculated over a year in the base 
Table 6

Economic and technical input data used in Eq. (27).

\begin{tabular}{|c|c|c|c|}
\hline Nomenclature & Unit & Meaning & Assumed value \\
\hline LCOE & $€ / \mathrm{kWh}$ & Levelized Cost of Electricity & - \\
\hline $\mathrm{T}$ & years & Economic lifetime of the PV system & 30 , according to [62]. \\
\hline $\mathrm{t}$ & - & year $t$ & - \\
\hline $\mathrm{C}_{\mathrm{t}}$ & $€$ & $\begin{array}{l}\text { Operation \& Maintenance }(O \& M) \text { costs and equipment } \\
\text { changes. }\end{array}$ & $\begin{array}{l}65 € / \mathrm{kW}_{\mathrm{p}} \text { per year [62] + PV Inverter replacement at } 15 \text { years }[18,62]+\text { replacing } \\
\text { batteries every } 7.3 \text { years (see Section } 6.1 .1 \text { ). }\end{array}$ \\
\hline $\mathrm{E}_{\mathrm{t}}$ & $\mathrm{kWh}$ & PV electricity generated on year $t$ & $E_{p v}$ \\
\hline I & $€$ & Initial investment & PV: ranging from $0.5 €$ to $2 €$ per $\mathrm{W}_{\mathrm{p}}$. + BESS: ranging from $100 €$ to $300 €$ per $\mathrm{kWh}$. \\
\hline $\mathrm{r}$ & $\%$ & Discount rate & $4.9 \%$ in Spain $[62]$. \\
\hline
\end{tabular}

Table 7

Comparison of three different models of battery lifetime.

\begin{tabular}{llll}
\hline & $\begin{array}{l}\text { Equivalent full } \\
\text { cycles }\end{array}$ & $\begin{array}{l}\text { Ah throughput } \\
\text { model }\end{array}$ & $\begin{array}{l}\text { Kinetic Battery } \\
\text { Model }\end{array}$ \\
\hline $\begin{array}{c}\text { Battery lifetime } \\
\text { (years) }\end{array}$ & 9.2 & 11.1 & 7.3 \\
\hline
\end{tabular}

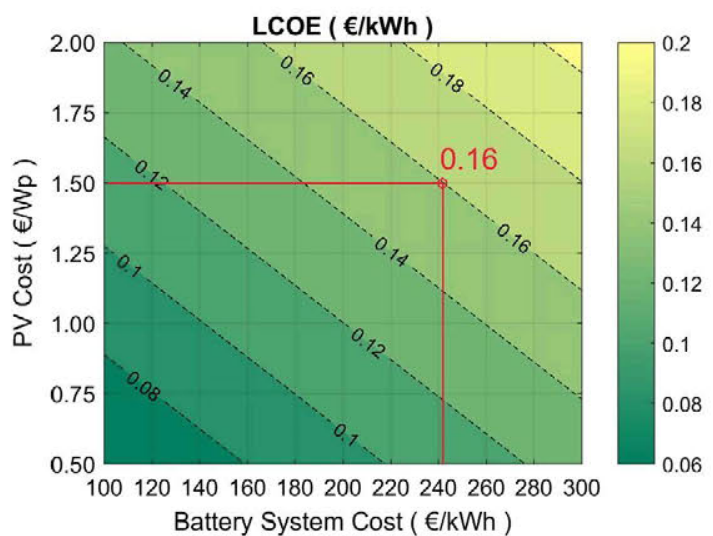

Fig. 17. Variation of LCOE depending on the cost of both PV and battery systems.

case without PV-battery system and compared to two cases. In the first one, only the PV system is considered (no BESS), and in the second one, both PV and BESS systems are considered. The invoice is divided into three values: power, energy, and taxes, as shown in Fig. 19.

From Fig. 19, it can be seen that only using a PV system $\left(2.68 \mathrm{~kW}_{\mathrm{p}}\right)$ would have $21 \%$ of billing reduction. However, the PV-battery system $\left(2.68 \mathrm{~kW}_{\mathrm{p}}, 6 \mathrm{kWh}\right)$ would enhance the savings in billing up to $56 \%$.

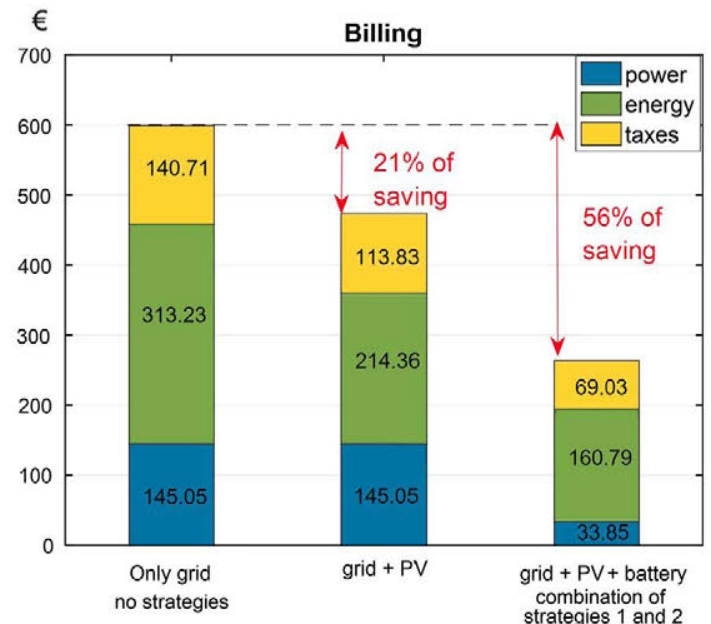

Fig. 19. Cost of imported grid electricity under three scenarios: original demand (left); after using PV system (center); and, after using PV - battery system (right).

\subsection{Sensitivity analysis}

The case study presented previously corresponds to a specific combination of PV-battery $\left(2.68 \mathrm{~kW}_{\mathrm{p}}\right.$ and $\left.6 \mathrm{kWh}\right)$. However, the variation of both PV and battery characteristics modifies the self-sufficiency (Fig. 20a), self-consumption, (Fig. 20b) and therefore, the billing savings (Fig. 20c). Thus, keeping the HVAC demand constant and using the same control strategies throughout the year (strategy 2 in winter/ summer; strategy 1 in spring/autumn), multiple simulations were performed varying the battery size between 0 to $10 \mathrm{kWh}$ (viable sizes for residential buildings), and the PV system size between 0.5 to $7 \mathrm{~kW}_{\mathrm{p}}$ (covering all fields of Magic Box).

The sensitivity analysis is useful to understand how the sizing of both PV and battery impacts the hybrid system. For example, setting a

\section{Payback time (years)}

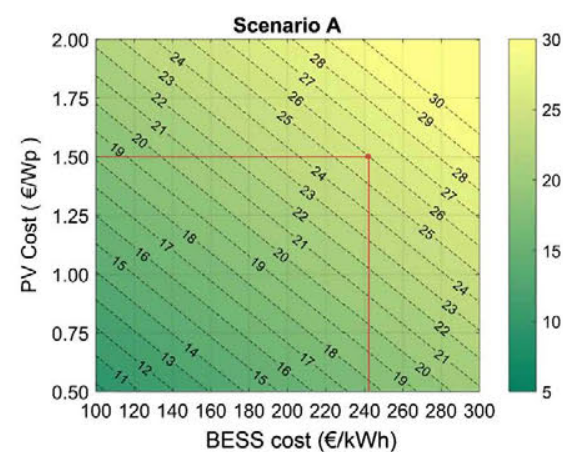

(a)

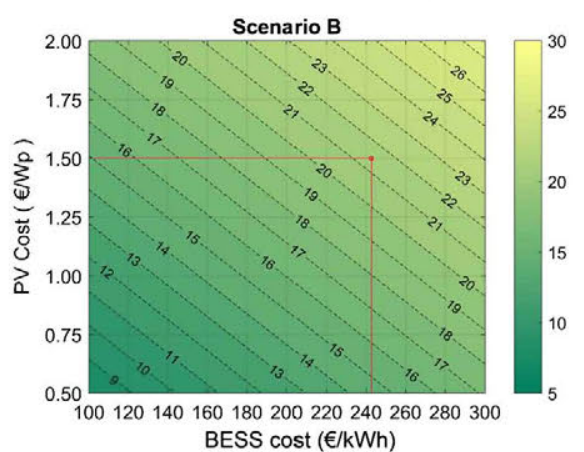

(b)

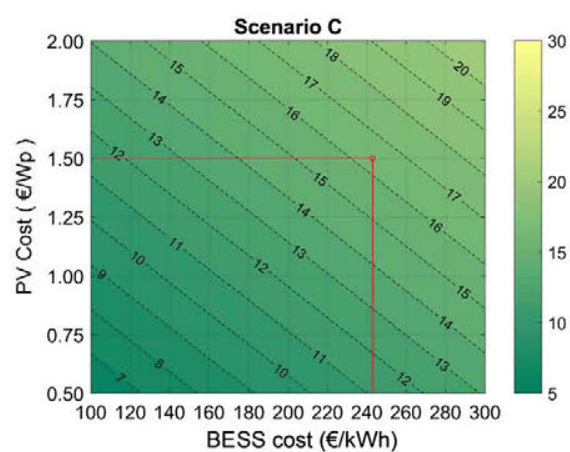

(c)

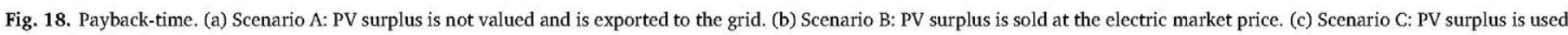
to supply other loads. 


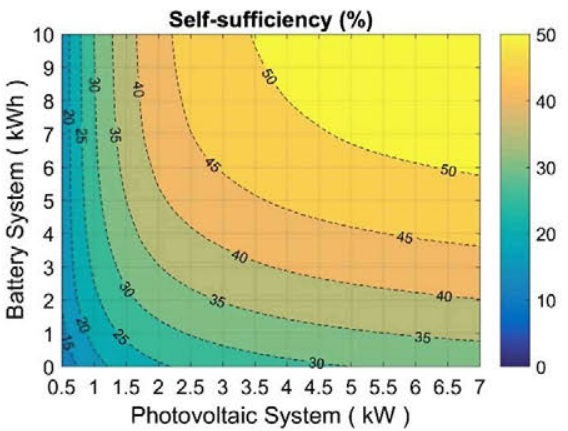

(a)

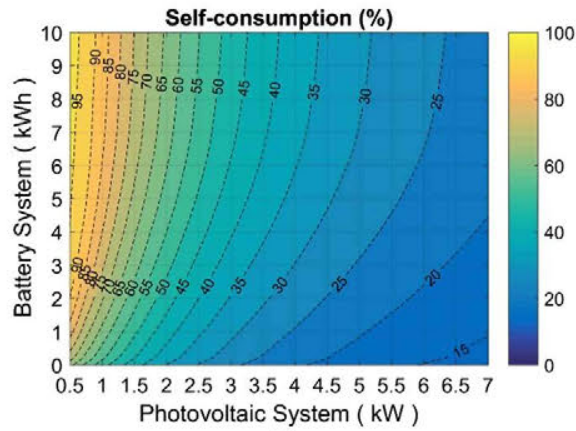

(b)

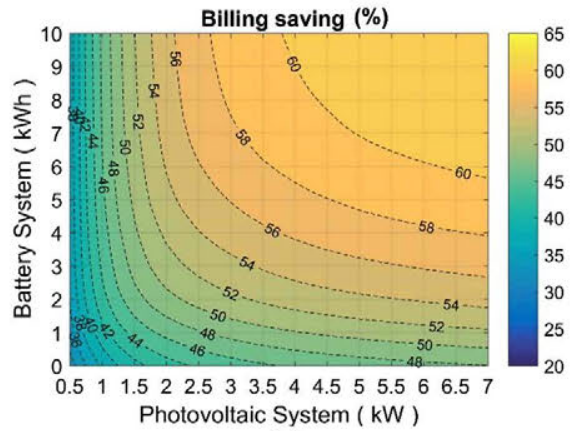

(c)

Fig. 20. (a) Self-sufficiency, (b) self-consumption, and (c) billing saving percentage with different battery size and different PV nominal power. HVAC load is constant.

PV system of $2.68 \mathrm{~kW}$, higher BESS sizes to $6 \mathrm{kWh}$ does not significantly increase self-sufficiency (Fig. 20a). It is also worth noting that the combination of strategies affects the value of billing, even in cases where there is no battery ( $0 \mathrm{kWh}$ in Fig. 20c), whereas small PV systems -less than $1 \mathrm{~kW}$ - allow billing savings around $40 \%$.

The self-sufficiency, self-consumption, and billing savings rate increments are not linear with the BESS capacity, suggesting that the optimal size of the PV-battery system is a crucial factor to be established, based on different energy and economic approaches [16].

\section{Discussion of results}

The experimental measurements have confirmed that the comfort conditions are within the levels established by widely used standards. In the same way, these measurements allowed the elaboration of the HVAC electrical consumption for the entire year and to develop strategies of control in order to increase self-consumption and decrease power demand.

The BESS control strategies used here allow one to reduce
W

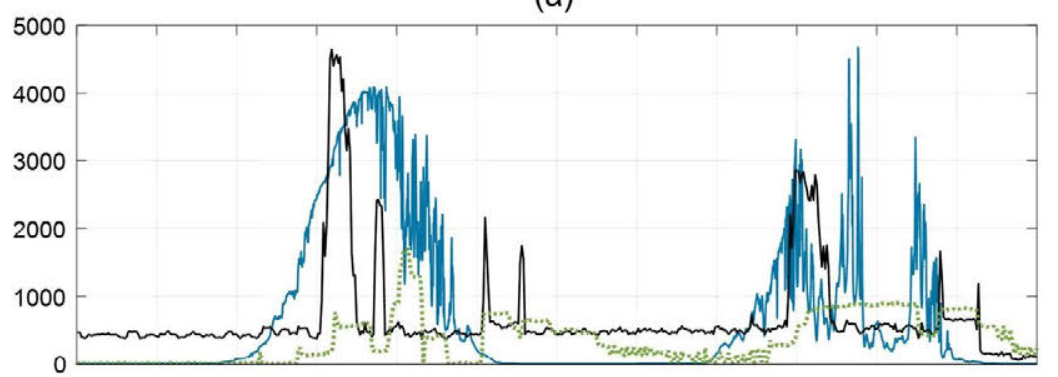

(b)

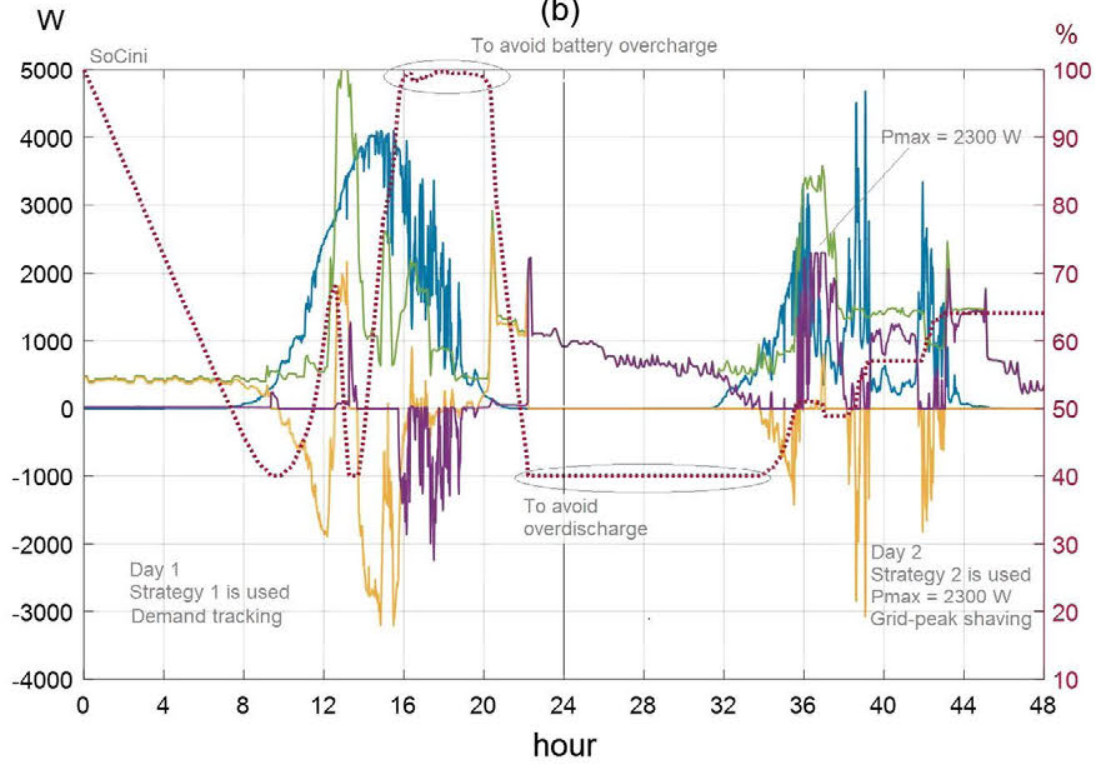

input data: - Ppv $\cdots$ Phvac - Pbuilding - Pload $=$ Phvac + Pbuilding

output data: - Pbat - Pgrid - SoC
Fig. 21. Two days operation of the battery control strategies proposed. (a) PV generation and building consumption. (b) Dynamic interaction between $P_{p v}, P_{l o a d}, P_{b a t}, P_{\text {grid }}$ and $S o C$, using strategy 1 for day 1 , and strategy 2 for day 2 . 
consumption of both energy and power from the grid. Strategy 1 is useful in electricity markets whose value of energy (kWh) is high, while strategy 2 is useful in electrical markets, such as the in Spain, where the contracted power $(\mathrm{kW})$ has a high cost in billing $(38.04 \mathrm{C} / \mathrm{kW} /$ year in 2016 for the residential sector, compared to $19.25 € / \mathrm{kW} /$ year in 2007) [41,42]. For the case study, the contracted power required for the HVAC system (according to the different standardized levels) is $3.45 \mathrm{~kW}$. However, using PV hybrid system, the contracted power is reduced to the smallest reasonable value: $0.805 \mathrm{~kW}$ ( $77 \%$ less). The combination of both strategies, as shown in Fig. 14, enables to limit the power from the grid in the months of peak demand (winter and summer) and to reduce grid electricity imports for the rest of the year.

In Fig. 18, scenario A (the least favourable), the consumer does not receive bonus for exporting PV surplus into the grid. In the second scenario, the consumer would be considered a prosumer, who is able to sell the PV surplus. However, this scenario depends on the political situation and regulations in each country. In contrast, this paper presents this scenario to provide evidence of the potential benefit that this type of system would have. The most realistic scenario is C, where PV surplus supplies other demands within the home (lights, appliances, machinery, electric vehicles, etc.). This scenario is the subject of further studies by the authors. Additionally, the authors are developing models for other types of batteries - specifically Lithium batteries- which have other characteristics, maximum and minimum states of charge, cost, etc. This will provide other studies and different results.

The model and battery control strategies presented in this paper are also applicable for other realistic situations, where HVAC power consumption is only a part of the total building load. In order to illustrate this situation, electrical consumption of two consecutive days is shown in Fig. 21a, where both HVAC $\left(P_{\text {hvac }}\right)$ and other load consumption ( $P_{\text {building }}$ ) such as electric vehicle, home appliances, and office equipment are plotted. Fig. 21a also shows PV generation of two days of experimental measurements (27 and 28 May 2017) where day 1 is a sunny day with cloudy intervals, and day 2 is a cloudy day. In this scenario, the strategy 1 operation is illustrated on the first day, where the battery can be charged with PV surplus. Day 2 uses strategy 2 (setting $P_{\max }$ at $2300 \mathrm{~W}$ which is a value equivalent to the maximum expected power) allowing the battery to keep enough capacity longer. In Fig. 21b dynamic results of the grid-connected PV-battery system and the battery state of charge are shown.

Another important aspect to consider in a realistic situation is the quality of data. The input data can be obtained from simulations from software tools (typically hourly values) or from measured data. Time resolution is a very important factor in the accuracy of the model, as indicated in $[71,72]$, where the results will be more reliable with subhourly data, especially to capture the high-peak powers. Once $P_{p v}$ and $P_{\text {load }}$ are entered, the model works to obtain $P_{\text {bat }}, P_{\text {grid }}$ and $S o C$ in each time-step, depending on the control strategy used.

\section{Conclusions}

In this paper, theoretical and experimental works that are being carried out in a grid-connected residential building prototype available at the IES-UPM have been presented. In particular, the following conclusions have been drawn from the analysis done on the influence of the specific application and the BESS control strategy.

(a) The mathematical model presented here has been developed for grid-connected PV-battery systems; as long as the battery is only charged with the PV surplus, it will never be charged from the grid. Although the focus of this article is the HVAC demand, the model is valid for other types of load $\left(P_{\text {load }}\right)$ inside the house. According to the experimental data, the theoretical model has an error margin lower than $10 \%$.

(b) It is important to know the annual distribution of electrical loads to determine which season or hourly periods with higher power demand justify the existence of some kind of strategy allowing consumption from the grid to be reduced. In this paper, two strategies have been proposed: the first helps to reduce energy consumption, and the second helps to reduce power peak demand from the grid. In the case study considered (Magic Box: $2.68 \mathrm{~kW}_{\mathrm{p}}$ coupled to a $6 \mathrm{kWh} / 48 \mathrm{~V}$ Lead-Acid battery with bidirectional inverter; annual PV generation comparable to HVAC demand), when using a combination of both strategies, it is possible to reduce both contracted power and energy consumption ( $77 \%$ and $49 \%$ respectively for case study).

(c) The implementation of local PV and electrical storage systems to power HVAC loads improves the self-sufficiency rate in varying degrees, depending not only on the PV power, but also on the HVAC load and storage control capacity. This behaviour implies that the optimal sizing of PV \& BESS must be carried out in each case by considering both energy and economic aspects.

(d) It is clear that, at present, the billing saving by itself might not be enough to encourage the use of PV hybrid systems. It will also strongly depend on the electricity tariff structure and energy policy in each country, in addition to PV and storage systems costs. This will determine whether the investment will be profitable from the financial point of view.

\section{Acknowledgements}

This work has been partially financed by the Spanish Ministry of Economy and Competitiveness within the framework of the project 'DEMS: Sistema distribuido de gestión de energía en redes eléctricas inteligentes' (TEC2015-66126-R).

The authors gratefully acknowledge the financial support by the National Secretary of Higher Education, Science, Technology and Innovation of Ecuador (SENESCYT) for a PhD scholarship to the first author.

The authors also acknowledge support of the 'Fundación Iberdrola España' by means of the '2015 Ayudas a la Investigación en Energía y Medio Ambiente' in the 'Smart Grids para la eficiencia en redes eléctricas: caso práctico en la ETSIT-UPM' project.

\section{References}

[1] Chua KJ, Chou SK, Yang WM, Yan J. Achieving better energy-efficient air conditioning - a review of technologies and strategies. Appl Energy 2013;104:87-104. http://dx.doi.org/10.1016/j.apenergy.2012.10.037.

[2] Perez-Lombard L, Ortiz J, Maestre IR. The map of energy flow in HVAC systems. Appl Energy 2011;88:5020-31. http://dx.doi.org/10.1016/j.apenergy.2011.07. 003.

[3] Eicker U, Colmenar-Santos A, Teran L, Cotrado M, Borge-Diez D. Economic evaluation of solar thermal and photovoltaic cooling systems through simulation in different climatic conditions: an analysis in three different cities in Europe. Energy Build 2014;70:207-23. http://dx.doi.org/10.1016/j.enbuild.2013.11.061.

[4] Hartmann N, Glueck C, Schmidt FP. Solar cooling for small office buildings: comparison of solar thermal and photovoltaic options for two different European climates. Renew Energy 2011;36:1329-38. http://dx.doi.org/10.1016/j.renene.2010. 11.006.

[5] Li Y, Zhang G, Lv GZ, Zhang AN, Wang RZ. Performance study of a solar photovoltaic air conditioner in the hot summer and cold winter zone. Sol Energy 2015;117:167-79. http://dx.doi.org/10.1016/j.solener.2015.04.015.

[6] IEA-SHC. New generation solar cooling \& heating systems. Task 53 2016; 2016.

[7] Solano J, Olivieri L, Caamaño E, Egido M. Climatización eficiente mediante bombas de calor y tecnología solar fotovoltaica: Análisis de viabilidad económica en edificios comerciales en España. XIII Congr. Ibero-americano Clim. y Refrig. Madrid; 2015.

[8] Turner WJN, Walker IS, Roux J. Peak load reductions: electric load shifting with mechanical pre-cooling of residential buildings with low thermal mass. Energy 2015;82:1057-67. http://dx.doi.org/10.1016/j.energy.2015.02.011.

[9] De Coninck R, Baetens R, Verbruggen B, Driesen J, Saelens D, Helsen L. Modelling and simulation of a grid connected photovoltaic heat pump system with thermal energy storage using Modelica. In: 8th Int Conf Syst Simul Build 2010; 2010. p. $1-21$.

[10] Daut I, Adzrie M, Irwanto M, Ibrahim P, Fitra M. Solar powered air conditioning system. Energy Proc 2013;36:444-53. http://dx.doi.org/10.1016/j.egypro.2013. 07.050 .

[11] Williams CJC, Binder JO, Kelm T. Demand side management through heat pumps, 
thermal storage and battery storage to increase local self-consumption and grid compatibility of PV systems. IEEE PES Innov Smart Grid Technol Conf Eur 2012:1-6. http://dx.doi.org/10.1109/ISGTEurope.2012.6465874.

[12] Thygesen R, Karlsson B. Simulation and analysis of a solar assisted heat pump system with two different storage types for high levels of PV electricity self-consumption. Sol Energy 2014;103:19-27. http://dx.doi.org/10.1016/j.solener.2014 02.013

[13] Aguilar FJ, Quiles PV, Aledo S. Operation and energy efficiency of a hybrid air conditioner simultaneously connected to the grid and to photovoltaic panels. Energy Proc 2014;48:768-77. http://dx.doi.org/10.1016/j.egypro.2014.02.089.

[14] Poullikkas A. A comparative overview of large-scale battery systems for electricity storage. Renew Sustain Energy Rev 2013;27:778-88. http://dx.doi.org/10.1016/j rser.2013.07.017.

[15] Achaibou N, Haddadi M, Malek A. Modeling of lead acid batteries in PV systems. Energy Proc 2012;18:538-44. http://dx.doi.org/10.1016/j.egypro.2012.05.065.

[16] Weniger J, Tjaden T, Quaschning V. Sizing of residential PV battery systems. Energy Proc 2014;46:78-87. http://dx.doi.org/10.1016/j.egypro.2014.01.160.

[17] de Oliveira e Silva G, Hendrick P. Lead-acid batteries coupled with photovoltaics for increased electricity self-sufficiency in households. Appl Energy 2016;178:856-67. http://dx.doi.org/10.1016/j.apenergy.2016.06.003.

[18] Hoppmann J, Volland J, Schmidt TS, Hoffmann VH. The economic viability of battery storage for residential solar photovoltaic systems - a review and a simulation model. Renew Sustain Energy Rev 2014;39:1101-18. http://dx.doi.org/10 1016/j.rser.2014.07.068.

[19] Linssen J, Stenzel P, Fleer J. Techno-economic analysis of photovoltaic battery systems and the influence of different consumer load profiles. Appl Energy 2017;185:2019-25. http://dx.doi.org/10.1016/j.apenergy.2015.11.088.

[20] Ciez RE, Whitacre JF. Comparative techno-economic analysis of hybrid micro-grid systems utilizing different battery types. Energy Convers Manage 2016;112:435-44. http://dx.doi.org/10.1016/j.enconman.2016.01.014

[21] Purvins A, Papaioannou IT, Debarberis L. Application of battery-based storage systems in household-demand smoothening in electricity-distribution grids. Energy Convers Manage 2013;65:272-84. http://dx.doi.org/10.1016/j.enconman.2012. 07.018.

[22] Quoilin S, Kavvadias K, Mercier A, Pappone I, Zucker A. Quantifying self-consumption linked to solar home battery systems: statistical analysis and economic assessment. Appl Energy 2016;182:58-67. http://dx.doi.org/10.1016/j.apenergy. 2016.08.077.

[23] Salpakari J, Lund P. Optimal and rule-based control strategies for energy flexibility in buildings with PV. Appl Energy 2016;161:425-36. http://dx.doi.org/10.1016/j. apenergy.2015.10.036.

[24] Moshövel J, Kairies KP, Magnor D, Leuthold M, Bost M, Gährs S, et al. Analysis of the maximal possible grid relief from PV-peak-power impacts by using storage systems for increased self-consumption. Appl Energy 2015;137:567-75. http://dx doi.org/10.1016/j.apenergy.2014.07.021.

[25] Li J, Danzer MA. Optimal charge control strategies for stationary PV battery systems. J Power Sources 2014;258:365-73. http://dx.doi.org/10.1016/j.jpowsour. 2014.02.066.

[26] Castillo-Cagigal M, Caamaño-Martín E, Matallanas E, Masa-Bote D, Gutiérrez A, Monasterio-Huelin F, et al. PV self-consumption optimization with storage and Active DSM for the residential sector. Sol Energy 2011;85:2338-48. http://dx.doi. org/10.1016/j.solener.2011.06.028.

[27] Bortolini M, Gamberi M, Graziani A. Technical and economic design of photovoltaic and battery energy storage system. Energy Convers Manage 2014;86:81-92. http:// dx.doi.org/10.1016/j.enconman.2014.04.089.

[28] Salom J, Marszal AJ, Widén J, Candanedo J, Lindberg KB. Analysis of load match and grid interaction indicators in net zero energy buildings with simulated and monitored data. Appl Energy 2014;136:119-31. http://dx.doi.org/10.1016/j. apenergy.2014.09.018.

[29] Tina G, Gagliano S, Raiti S. Hybrid solar/wind power system probabilistic modelling for long-term performance assessment. Sol Energy 2006;80:578-88. http://dx. doi.org/10.1016/j.solener.2005.03.013.

[30] Kanase-Patil AB, Saini RP, Sharma MP. Integrated renewable energy systems for off grid rural electrification of remote area. Renew Energy 2010;35:1342-9. http://dx. doi.org/10.1016/j.renene.2009.10.005.

[31] Calvo-Fernandez M, Vega JE, Egido MA. Spanish participation in the "Solar Decathlon 2005": design and simulation of the photovoltaic system. In: 20th EU Photovolt Conf; 2005. p. 1958-63.

[32] PVdatabase. PV database. Building integrated and urban photovoltaic solar energy projects and products 2007 . < http://www.pvdatabase.org/projects view_details. php?ID = 203> [accessed June 21, 2017]

[33] Castillo-Cagigal M, Gutiérrez A, Monasterio-Huelin F, Caamaño-Martín E, Masa D, Jimenéz-Leube J. A semi-distributed electric demand-side management system with PV generation for self-consumption enhancement. Energy Convers Manage 2011;52:2659-66. http://dx.doi.org/10.1016/j.enconman.2011.01.017.

[34] Masa-Bote D, Castillo-Cagigal M, Matallanas E, Caamaño-Martín E, Gutiérrez A, Monasterio-Huelin F, et al. Improving photovoltaics grid integration through short time forecasting and self-consumption. Appl Energy 2014;125:103-13. http://dx. doi.org/10.1016/j.apenergy.2014.03.045.

[35] Masa-Bote D, Caamaño-Martin E. Methodology for estimating building integrated photovoltaics electricity production under shadowing conditions and case study. Renew Sustain Energy Rev 2014;31:492-500. http://dx.doi.org/10.1016/j.rser. 2013.12.019.

[36] Macagnan M, Lorenzo E, Jiménez C. Solar radiation in Madrid. Int J Sol Energy 1994;16. http://dx.doi.org/10.1080/01425919408914262.

[37] World Energy Council. E-storage : shifting from cost to value. Wind and solar applications. World future energy summit; 2016. p. 1-14.

[38] Mulder G, Six D, Claessens B, Broes T, Omar N, Van Mierlo J. The dimensioning of PV-battery systems depending on the incentive and selling price conditions. Appl Energy 2013;111:1126-35. http://dx.doi.org/10.1016/j.apenergy.2013.03.059.

[39] Doeff MM. Batteries for sustainability 2013. http://dx.doi.org/10.1007/978-14419-0851-3.

[40] Misra SS, Mraz SL, Dillon JD, Swanson DB. VRCA Battery with AGM-Gel Hybrid for Superior Performance 2003:378-82.

[41] RD 1634/2006. Ministerio de industria, turismo y comercio 22961; 2006. p. 46656-79.

[42] Ministerio de Industria Energía y Turismo de España. Orden IET-107-2014: Peajes de acceso de energía eléctrica. Boletín Of Del Estado; 2014. p. 27548-62.

[43] Widén J. Improved photovoltaic self-consumption with appliance scheduling in 200 single-family buildings. Appl Energy 2014;126:199-212. http://dx.doi.org/10. 1016/j.apenergy.2014.04.008.

[44] Palensky P, Dietrich D. Demand side management: demand response, intelligent energy systems, and smart loads. IEEE Trans Ind Inf 2011;7:381-8. http://dx.doi. org/10.1109/TII.2011.2158841.

[45] Leadbetter J, Swan L. Battery storage system for residential electricity peak demand shaving. Energy Build 2012;55:685-92. http://dx.doi.org/10.1016/j.enbuild.2012. 09.035.

[46] Yang Y, Li H, Aichhorn A, Zheng J, Greenleaf M. Sizing strategy of distributed battery storage system with high penetration of photovoltaic for voltage regulation and peak load shaving. IEEE Trans Smart Grid 2014;5:982-91. http://dx.doi.org/ 10.1109/TSG.2013.2282504.

[47] Schmidt H, Sauer DU. Praxisgerechte und präzise Modellierung von WechselrichterWirkungsgraden. In: IX Int Sol Forum; 1994.

[48] Luthander R, Widén J, Nilsson D, Palm J. Photovoltaic self-consumption in buildings: a review. Appl Energy 2015;142:80-94. http://dx.doi.org/10.1016/j. apenergy.2014.12.028.

[49] Holopainen R, Tuomaala P, Hernandez P, Häkkinen T, Piira K, Piippo J. Comfort assessment in the context of sustainable buildings: comparison of simplified and detailed human thermal sensation methods. Build Environ 2014;71:60-70. http:// dx.doi.org/10.1016/j.buildenv.2013.09.009.

[50] Fanger PO et al. Thermal comfort. Analysis and applications in environmental engineering. New York, Copenhagen: Danish Technical Press; 1970.

[51] ISO. Ergonomics of the thermal environment: analytical determination and interpretation of thermal comfort using calculation of the PMV and PPD indices and local thermal comfort criteria. International Standard ISO 7730. International Organization for Standardization; 2005

[52] De Dear RJ, Brager GS. Thermal comfort in naturally ventilated buildings: revisions to ASHRAE standard 55. Energy Build 2002;34:549-61. http://dx.doi.org/10.1016/ S0378-7788(02)00005-1.

[53] Nicol JF, Humphreys MA. Thermal comfort as part of a self-regulating system. Build Res Pract 1973;1:174-9. http://dx.doi.org/10.1080/09613217308550237.

[54] ANSI/ASHRAE. Primary standard 55-2013. Thermal environmental conditions for human occupancy; 2013.

[55] Afram A, Janabi-Sharifi F. Theory and applications of HVAC control systems - a review of model predictive control (MPC). Build Environ 2014;72:343-55. http:// dx.doi.org/10.1016/j.buildenv.2013.11.016.

[56] Putta V, Kim D, Cai J, Hu J, Braun J, Lafayette W, et al. Distributed model predictive control for building HVAC systems: A case study. International High Performance Buildings Conference; 2014

[57] INDUSTRIA M DE, COMERCIO TY. Resolucion de la Dirección General de Política Energética y Minas, por la que se modifica la de 14 de marzo de 2006, por la que se establece la tabla de potencias normalizadas para todos los suministros en baja tensión. BOE Núm 231; 2006. p. 33821-33821.

[58] Moseley PT, Garche J, Parker CD, Rand DAJ. Valve-regulated lead-acid batteries. Elsevier B.V; 2004.

[59] Lang T, Gloerfeld E, Girod B. Don't just follow the sun - a global assessment of economic performance for residential building photovoltaics. Renew Sustain Energy Rev 2015;42:932-51. http://dx.doi.org/10.1016/j.rser.2014.10.077.

[60] Branker K, Pathak MJM, Pearce JM. A review of solar photovoltaic levelized cost of electricity. Renew Sustain Energy Rev 2011;15:4470-82. http://dx.doi.org/10. 1016/j.rser.2011.07.104.

[61] Breyer C, Gerlach A. Global overview on grid-parity. Prog Photovolt Res Appl 2013;21:121-36. http://dx.doi.org/10.1002/pip.1254.

[62] Creara. PV grid parity monitor: residential sector 3rd issue; 2015. p. 101.

[63] Dufo-López R, Lujano-Rojas JM, Bernal-Agustín JL. Comparison of different leadacid battery lifetime prediction models for use in simulation of stand-alone photovoltaic systems. Appl Energy 2014;115:242-53. http://dx.doi.org/10.1016/j. apenergy.2013.11.021.

[64] Bindner H, Cronin T, Lundsager P, Manwell JF, Abdulwahid U, Baring-gould I. Lifetime modelling of lead acid batteries 2005;1515

[65] Schiffer J, Sauer DU, Bindner H, Cronin T, Lundsager P, Kaiser R. Model prediction for ranking lead-acid batteries according to expected lifetime in renewable energy systems and autonomous power-supply systems. J Power Sources 2007;168:66-78. http://dx.doi.org/10.1016/j.jpowsour.2006.11.092.

[66] Sauer DU, Wenzl H. Comparison of different approaches for lifetime prediction of electrochemical systems-using lead-acid batteries as example. J Power Sources 2008;176:534-46. http://dx.doi.org/10.1016/j.jpowsour.2007.08.057.

[67] Jenkins D, Fletcher J, Kane D. Lifetime prediction and sizing of lead-acid batteries for microgeneration storage applications. Renew Power Gen IET 2008;2:191-200. http://dx.doi.org/10.1049/iet-rpg:20080021.

[68] IEA PVPS. Trends 2016 in photovoltaic applications; 2016

[69] Hosenuzzaman M, Rahim NA, Selvaraj J, Hasanuzzaman M, Malek ABMA, Nahar A. 
Global prospects, progress, policies, and environmental impact of solar photovoltaic power generation. Renew Sustain Energy Rev 2015;41:284-97. http://dx.doi.org/ 10.1016/j.rser.2014.08.046.

[70] Bernal-Agustín JL, Dufo-López R. Economical and environmental analysis of grid connected photovoltaic systems in Spain. Renew Energy 2006;31:1107-28. http:// dx.doi.org/10.1016/j.renene.2005.06.004.

[71] Cao S, Sirén K. Impact of simulation time-resolution on the matching of PV production and household electric demand. Appl Energy 2014;128:192-208. http://dx. doi.org/10.1016/j.apenergy.2014.04.075.

[72] Wright A, Firth S. The nature of domestic electricity-loads and effects of time averaging on statistics and on-site generation calculations. Appl Energy 2007;84:389-403. http://dx.doi.org/10.1016/j.apenergy.2006.09.008.

\section{Glossary}

ADSM: Active Demand Side Management

$B E S S:$ battery energy storage system

HVAC: heating, ventilation and air-conditioning

IEA: International Energy Agency

IES: Intituto de Energia Solar, Solar Energy Institute

LCOE: levelized cost of electricity

$M A E$ : Mean Absolute Error

$M P C$ : Model Predictive Control

$P M V$ : Predicted Mean Vote Index

PV: photovoltaic

SMAPE: symmetric mean absolute percent error 